\title{
Gente Joven: Un diálogo sobre la sexualidad con adolescentes mexicanos
}

Magaly Marques

John M. Paxman

Judith Bruce

Population Council

Follow this and additional works at: https://knowledgecommons.popcouncil.org/departments_sbsr-pgy

Part of the Family, Life Course, and Society Commons, Gender and Sexuality Commons, International Public Health Commons, Maternal and Child Health Commons, Public Health Education and Promotion Commons, and the Women's Health Commons How does access to this work benefit you? Let us know!

\section{Recommended Citation}

Marques, Magaly, John M. Paxman, and Judith Bruce. 1996. "Gente Joven: Un diálogo sobre la sexualidad con adolescentes mexicanos," Quality/Calidad/Qualité no. 5. New York: Population Council. 
Quality/Calidad/Qualité es una publicatión del Population Council que documenta ejemplos de programas de planificación familiar y salud reproductiva que proveen un nivel de calidad de atención estraordinariamente alto. Esta serie forma parte del Programa Robert H. Ebert sobre Temas Críticos en Salud Reproductiva y Población, un programa del Council que busca mejorar y ampliar el alcance y la calidad de la atención en salud reproductiva a través de iniciativas científicas y prácticas. La base filosófica del programa, y de esta serie, es el derecho fundamental de las mujeres y sus parejas al trato respetuoso, la información, las opciones y el seguimiento por parte de los proveedores de atención en salud reproductiva. Los folletos reflejan uno de los cuatro impulsos principales del programa: aumentar la calidad de los programas de planificación familiar.

Los proyectos que se incluyen en Quality/Calidad/Qualité son seleccionados por un Comité Asesor de individuos que representan una amplia gama de experiencia en el ámbito de la salud reproductiva, y que están comprometidos a mejorar la calidad de atención. Los proyectos se eligen por estar logrando importantes avances en por los menos uno de los siguientes aspectos: ampliar la gama de opciones de métodos y technologías anticonceptivas disponsibles; proporcionar la informatión que las clientes necesitan para hacer elecciones informadas y para controlar mejor su salud reproductiva; mejorar la calidad del trato entre proveedor y cliente, promoviendo la continuación del contacto entre ambos; iniciar proyectos innovadores para aumentar la capacidad administrativa y ampliar el nivel de capacitatión de los proveedores de servicios a todo nivel; extender la gama de servicios en informatión más allá de los que convencionalmente se define como "planificación familiar"; y alcanzar, con los servicios de salud reproductiva, a grupos que generalmente no los reciben.

Ninguno de los proyectos incluidos en la serie se está presentando como un modelo para la replicación. Se ofrecen más bien como un ejemplo singularmente creativo de valores, objectivos y aplicación de ideas. Estas son "experiencias de aprendizaje" que ilustran la necesidad de mantener una actitud autocrítica para anticipar las necesidades de las clientes y para encontrar medios económicos de satisfacerlas. Esta actitud reflexiva se manifiesta en la voluntad de responder a los cambios en las necesidades de las clientes y en las transformaciones económicos y sociales en general. Esperamos que la documentación de las decisiones críticas que estos programas han tenido que hacer ayudará a reforzar en términos prácticos, la evidencia de que la satisfacción del individuo con los servicios de salud reproductiva está fuertemente ligada al logro de objectivos más amplios en salud y población.

La publicación de esta edición de Quality/Calidad/Qualité en español fue posible gracias al apoyo de la Fundación Ford, la John D. and Catherine T. MacArthur Foundation y la Autoridad para el Desarrollo Internacional de Suecia.
Las declaraciones y opiniones expresadas en esta publicación son la responsabilidad exclusiva del autor y no necesariamente representan la posición de las organizaciones que proveen apoyo a Quality/Calidad/Qualité. 


\title{
Gente Joven: \\ Un diálogo sobre la sexualidad con adolescentes mexicanos
}

\author{
Por Magaly Marques \\ Introducción de John M. Paxman \\ Conclusión de Judith Bruce
}

\section{Introducción}

El subtítulo de este número, "Un diálogo sobre la sexualidad con adolescentes mexicanos", busca llamar la atención al hecho de que la gran parte de los programas de educación sexual para jóvenes han sido elaborados por adultos que ignoran la realidad de la adolescencia como la percibe el adolescente. El tratamiento que muchas sociedades le dan a la sexualidad adolescente hace recordar el famoso cuento de Hans Christian Andersen, "Las nuevas ropas del emperador". En el cuento, los sastres de un emperador egoísta logran convencerlo de que sus nuevas ropas están hechas de una tela mágica e invisible, cuando en realidad lo han dejado desnudo. El pueblo, negando lo que el sentido común y sus propios ojos indican, sumisamente participa en el engaño, hasta que un niño, viendo al emperador en un desfile, grita: “¡El emperador está desnudo!” Sólo entonces se animan los demás a reconocer lo que sus propios ojos les indicaban.

Del mismo modo, cuando se trata de sexualidad adolescente, muchos tratamos de ignorar una realidad amenazante. Por mucho tiempo, padres, políticos, directores de programas e incluso algunos jóvenes se han negado a enfrentar dicha realidad. Se ha tratado de negar, por ejemplo, que una importante proporción de los adolescentes en todo el mundo son sexualmente activos, ya sean casados o solteros. Pero la investigación indica que existen más de mil millones de jóvenes entre 10 y 19 años de edad en el mundo; que la mayoría de las mujeres en los países en vías de desarrollo tienen hijos o se hacen un aborto antes de cumplir 19; y que los varones suelen iniciar su actividad sexual antes que las mujeres.

Pero aunque estemos de acuerdo en reconocer que los adolescentes tienen relaciones sexuales, quedan muchas difíciles cuestiones por resolver. ¿Es apropiada dicha actividad sexual? ¿Cuáles son sus consecuencias? ¿Qué factores determinan la actividad sexual y anticonceptiva entre los adolescentes? Y por último, ¿Qué tipos de programas resultan más eficaces cuando se trata de educar a los jóvenes sobre sexualidad y anticoncepción? Estas son sólo algunas de las preguntas que siguen desafiando a padres, familias y comunidades, así como a profesionales en salud y educación.

\section{Factores que influyen en la actividad sexual y el uso de anticonceptivos entre adolescentes}

Antes de elaborar programas para adolescentes en una sociedad determinada, es importante conocer las características de la actividad sexual y el uso de anticonceptivos entre los adolescentes de dicha sociedad. En eso influye fundamentalmente el nivel de desarrollo económico y social de un país.

La mayoría de las sociedades tradicionales consideraban normal la sexualidad femenina en la adolescencia, siempre y cuando fuera determinada y controlada por el matrimonio. En las sociedades rurales tradicionales, las ventajas económicas y sociales de un alto nivel de fertilidad contribuían a dicha actitud. Incluso en la actualidad, en sociedades donde perduran normas tradicionales, el matrimonio sigue siendo el contexto principal para la gran parte de la actividad sexual adolescente, el aborto por lo general es ilegal, y el tamaño preferido de familia sigue siendo relativamente grande. 
A medida que las sociedades tienden hacia la urbanización y la modernización, la expansión de oportunidades económicas y educacionales, y los cambios en los roles de las mujeres, tienen como resultado matrimonios y madres que tienen su primer hijo a una edad más tardía. Estos factores suelen debilitar los lazos familiares y el acatamiento a las normas culturales tradicionales. También suelen conducir a un aumento en el uso de anticonceptivos. La actividad sexual de los adolescentes, no regulada primordialmente ya por el matrimonio, se hace más esporádica; pero al mismo tiempo resulta más difícil de controlar, dada la disminuída influencia de las sanciones en contra del sexo pre-matrimonial.

\section{Consecuencias de la actividad sexual entre adolescentes}

Los padres por lo general esperan que sus hijos lleguen a ser adultos con actitudes positivas, naturales y responsables hacia el sexo y la intimidad. Pero el cuándo y bajo qué condiciones de la actividad sexual suele ser una cuestión de valores. De cualquier modo, la actividad sexual precoz suele tener serias consecuencias. Aunque éstas afectan a jóvenes de ambos sexos, suelen ser mucho más graves para mujeres que para varones.

El embarazo, por ejemplo, tiene consecuencias dispares para muchachas y muchachos. Es menos probable que el varón culpable de un embarazo sufra el mismo ostracismo social y moral que la mujer. Dicho varón no estará obligado a dejar de asistir a la escuela y no tendrá que sufrir el oprobio y el gasto económico asociados con un aborto clandestino. De hecho, muchos muchachos logran evadir casi del todo su responsabilidad social y económica en la crianza de hijos. En consecuencia, los varones adolescentes suelen preocuparse menos por la anticoncepción, y en algunos casos hasta se oponen a que sus parejas la utilicen. Además de estas desigualdades, las mujeres cargan con el riesgo físico del embarazo y el parto precoz. Cuando niños engendran niños, los índices de morbilidad y mortalidad, tanto para madres como bebés, son mucho más altos que en los casos de mujeres que son madres en la edad adulta, especialmente cuando se carece de antención prenatal adecuada. Las muchachas también asumen el riesgo físico asociado con abortos clandestinos y con las enfermedades de transmisión sexual (ETS). La probabilidad de que una ETS no reciba atención médica es mayor entre mujeres, afectando así su salud y fertilidad futuras.

Es más, la pandemia del SIDA ha introducido otra dimensión potencialmente fatal a la actividad sexual precoz. En la actualidad casi la cuarta parte de la población mundial infectada con el virus que causa el SIDA tiene menos de treinta años, lo cual indica que la mayoría contrae el virus durante la adolescencia. En algunos países donde los niveles de infección entre varones ya son altos, muchos hombres se esfuerzan en encontrar mujeres cada vez más jóvenes, suponiendo que así se protegen sin tener que cambiar su comportamiento sexual. La necesidad de educar a los jóvenes sobre la prevención del SIDA añade un nuevo y urgente desafío al tema de la sexualidad adolescente.

\section{Características de programas eficaces}

Incluso si podemos llegar a un acuerdo sobre la realidad de la actividad sexual adolescente y concluir que debemos ofrecer educación sexual y acceso a servicios, quedan aún mil preguntas sobre el modo óptimo de lograr dichos objetivos. ¿Qué es precisamente lo que los jóvenes de hoy necesitan saber? ¿Cuándo, dónde y por medio de quién conviene que los jóvenes reciban educación sexual? ¿Es recomendable proveer con anticonceptivos a jóvenes que ya han iniciado la actividad sexual (incluso si no están casados), con el propósito de evitar embarazos no deseados y la transmisión de las ETS? ¿Quién debería proveer servicios anticonceptivos? ¿Dónde y cómo conviene ofrecerlos? ¿Es necesario consultar a los padres de una adolescente antes de darle anticonceptivos? ¿Da lo mismo con los padres de un varón? ¿Qué responsabilidades deberían ser asumidas por los adolescentes? Las adolescentes que quedan embarazadas sin desearlo, ¿deberían tener acceso a un aborto seguro y profesional?

La experiencia nos está empezando a dar una idea de los tipos de programas que resultan eficaces con adolescentes. Sabemos, por ejemplo, que los programas exitosos ofrecen información sobre sexualidad de un modo directo y abierto. Esta información debe ir más allá de los datos biológicos, ofreciéndole al adolescente una base sobre la cual puede decidir objetivamente sobre su comportamiento sexual en situaciones de vida real. Muchos programas de educación sexual tratan a los 
adolescentes como si la sexualidad fuera la única dimensión de sus vidas. Para ser eficaz, la información sobre sexualidad debe presentarse como una dimensión de la experiencia humana total, no como un fenómeno puramente clínico o biológico.

Los programas exitosos alcanzan a los jóvenes en su ambiente natural: las escuelas, centros de recreación, los lugares de trabajo y la calle. En muchos países en vías de desarrollo, la proporción de adolescentes que continúa estudiando después de la escuela primaria no alcanza al 10\%. Esto muestra la importancia de alcanzar a los jóvenes que no están en la escuela, que son generalmente los más difíciles, pero que pueden también tener la necesidad más grande.

Uno de los temas más controversiales de los programas para adolescentes es el ofrecimiento de servicios de anticoncepción. Los jóvenes se encuentran entre dos polos opuestos: los medios masivos de comunicación los alientan a explorar la sexualidad, mientras que sus padres, maestros y las autoridades religiosas insisten en la disciplina y la abstinencia. La investigación ha demostrado-muy a pesar de los esfuerzos de los que trabajan en este campo-que los adolescentes tienden a iniciar su vida sexual mucho antes de que les empiece a interesar el tema de la anticoncepción. Pero no es necesario que la actividad sexual entre adolescentes tenga como precio embarazos e hijos no deseados. La anticoncepción tiene que ver con el sentido común, y los programas más exitosos proveen acceso a la información, los métodos y los servicios necesarios. Como resumió John Paul Stevens, un famoso juez de la Corte Suprema de los Estados Unidos, en respuesta a un caso que trataba de prohibir la venta y distribución de condones entre jóvenes: "Es como si para demostrar su antipatía hacia las motocicletas, han optado por prohibir el uso de cascos".

Otro factor que influye fundamentalmente en la actividad sexual y el uso de anticonceptivos es el género. El mensaje que la sociedad da a los varones (a través de los medios masivos, los amigos o incluso a veces los padres) es que la actividad sexual es normal y les corresponde por derecho. Las adolescentes, en cambio, reciben el mensaje opuesto. Por un lado se les enseña que para una mujer la actividad sexual antes del matrimonio (e incluso el deseo en sí) es inmoral. Por otro, los medios masivos y otros jóvenes las incitan a ser sexualmente atractivas. Es más, una adolescente no se debe ver como "preparada" para el coito, para que no reciba el estigma de "demasiado fácil".

En consecuencia, muchos jóvenes (y especialmente las mujeres) no quieren reconocer el hecho de que son sexualmente activos, especialmente si dicha actividad es esporádica. Muchos también creen que el uso de anticonceptivos estropea el ambiente romántico y la espontaneidad de un encuentro sexual. Las muchachas temen que si demuestran demasiada preparación, sus parejas pensarán que son demasiado "fáciles"; si en cambio se "dejan llevar" por la emoción del momento, es más fácil pensar que nadie tiene la culpa. No es de extrañar entonces que el sólo ofrecer información y servicios a los adolescentes no garantiza que usen anticonceptivos.

Aunque los adultos, e incluso los padres, juegan un importante papel en la formulación de programas para adolescentes, casi todos reconocemos que los jóvenes tienen un vocabulario propio y una perspectiva distinta de la vida. Es más, esa perspectiva suele cambiar pronunciadamente de un año a otro durante esta tempestuosa etapa de la juventud. Por esa causa no debe sorprendernos que no suelen ser eficaces los programas para adolescentes basados exclusivamente en la perspectiva de adultos de otra generación. Los adolescentes son los que corren el riesgo y sufren las consecuencias de la actividad sexual. Los formuladores de programas deben considerar a la juventud como parte íntegra de cualquier propuesta, en vez de verlos como receptores pasivos de una "solución". La experiencia ha demostrado que la participación activa de los jóvenes, incluso en los ámbitos de planificación y administración, es un ingrediente fundamental para el éxito de dichos programas.

Este número de Quality/Calidad/Qualité relata la experiencia de Gente Joven, un programa de educación sexual para adolescentes en México. Gente Joven comenzó como el niño en el cuento de Andersen, reconociendo que los problemas relativos a la sexualidad no desaparecen por mucho que tratemos de negar su existencia. A través de los años los dirigentes de Gente Joven han aprendido, y siguen aprendiendo, muchas lecciones sobre cómo diseñar un programa eficaz para adolescentes. En estas páginas ellos comparten algunas de esas experiencias. En el epílogo, exploramos con mayor detalle un tema que Gente Joven ha identificado como su próximo gran desafío: una reconsideración del programa desde una perspectiva de género. 


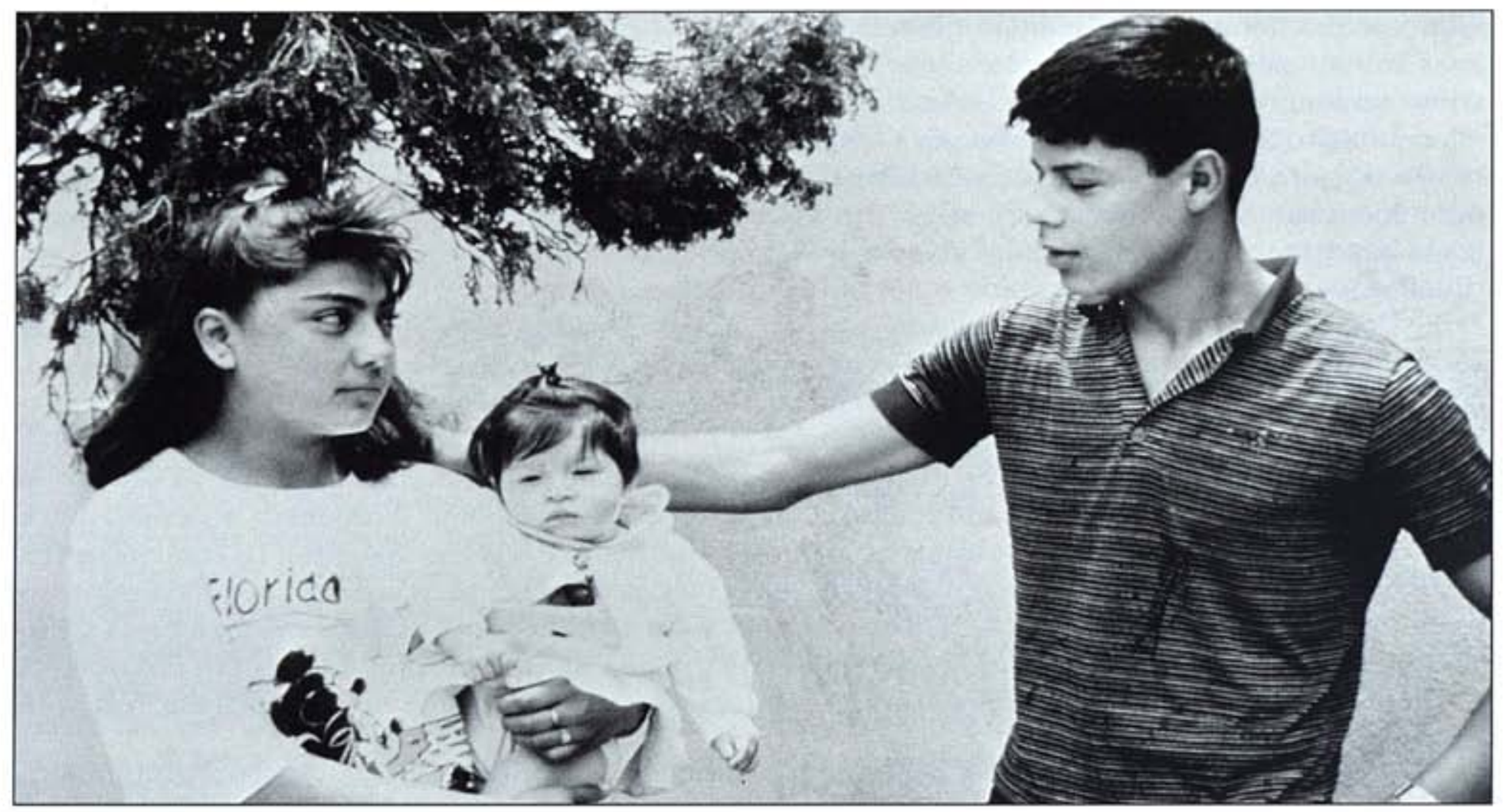

\section{El contexto}

Una cosa es tener ideas sobre el ofrecimiento de educación y servicios relativos a sexualidad y salud reproductiva para adolescentes. Organizar un programa que efectivamente pueda responder a las necesidades de los jóvenes es mucho más difícil. Cualquier organización que busca poner en marcha dicho programa debe enfrentar ciertas dificultades básicas:

- Los adultos son diferentes que los adolescentes

- Las muchachas son diferentes que los muchachos

- Los programas para adolescentes no generan recursos económicos

- Los adultos suelen oponerse a este tipo de programa

- Los programas de educación sexual son difíciles de evaluar, y los donantes quieren ver resultados cuantitativos.

Cuando la Fundación Mexicana Para la Planificación Familiar, (Mexfam, una entidad afiliada a IPPF, la International Planned Parenthood Federation), empezó a trabajar con jóvenes, inició un proceso que le obligó a confrontar cada una de estas dificultades. Para responder a las necesidades de los adolescentes, Mexfam ha tenido que redefinir todos los supuestos de sus programas de planificación familiar y reformular sus actividades. Partiendo de una base improvisada, Mexfam ha aprendido paulatinamente cuáles programas de educación sexual y servicios anticonceptivos son más eficaces. El proceso de evolución de Gente Joven continúa en la actualidad, en respuesta a la experiencia directa con jóvenes.

Mexfam, fundada en 1965, ofrece servicios de salud y planificación familiar a poblaciones de bajos ingresos fuera del alcance de los programas del gobierno. Mexfam también provee capacitación y entrenamiento para otras organizaciones de planificación familiar y servicios similares. En 1986, Mexfam decidió añadir un programa para adolescentes a su esquema de servicios, sobre la base de un análisis de información demográfica y resultado de encuestas, que indicaba que:

- Los adolescentes de entre 10 y 19 años de edad componen el $25 \%$ de la población de México (1)

- La edad promedio para el inicio de actividad sexual es 15,7 años para varones y 17 años para mujeres (2)

- Las escuelas públicas no ofrecían educación sexual 
- Una de las quejas más comunes de los jóvenes es la falta de comunicación entre adolescentes y adultos.

Los datos también indicaban que el 59,7\% de todos los embarazos entre adolescentes mexicanos no eran deseados (3), y el número de casos de enfermedades de transmisión sexual estaba aumentando. En resumen, dado que los jóvenes componen casi la mitad de la población mexicana, Mexfam decidió que era indispensable prestarle más atención al grupo que definirá el futuro del país.

\section{Diferencias entre adultos y adolescentes}

Gente Joven fue diseñado para llevar información sobre sexualidad y planificación familiar a jóvenes en las regiones urbanas marginales de México. Los dirigentes de Mexfam no tardaron en darse cuenta que toda la experiencia que tenían con programas para adultos no necesariamente era útil cuando se trataba de diseñar un programa específicamente para jóvenes. En efecto, era obvio que para intercambiar información sobre sexualidad con jóvenes, primero sería necesario superar la desconfianza de muchos jóvenes hacia consejos provenientes de adultos, y luego mejorar la pobre comunicación entre las dos generaciones. Hoy, muchos padres se quejan del comportamiento "imposible" de los jóvenes, los jóvenes acusan a los padres de falta de comprensión, y los maestros dicen que sus estudiantes se muestran cada vez más escépticos y muestran poca confianza en sus instructores.

Inicialmente, Gente Joven utilizó una estrategia similar a la de muchas entidades que trabajan con adolescentes. Mexfam inauguró tres centros especialmente para adolescentes (en Colima, Contreras y Ciudad de México) que ofrecían una variedad de actividades recreativas programadas, además de pláticas sobre sexualidad y planificación familiar. Los centros también ofrecían consultas médicas básicas (incluso consultas para anticoncepción) y varias actividades y servicios diseñados específicamente para las necesidades de la comunidad local. Básicamente, se esperaba que una vez que se lograra ganar la confianza de los jóvenes, éstos mostrarían interés en aprender sobre cómo evitar embarazos y enfermedades de transmisión sexual.
Entre 1986 y 1988, Mexfam inauguró un total de 13 centros para adolescentes (algunos independientes, otros en conexión a centros de Mexfam dedicados a planificación familiar). Una combinación de empleados de Mexfam y adolescentes de la comunidad local que funcionaban como promotores de Gente Joven, trabajaba para difundir el programa e invitar a nuevos participantes. Mario Zárate, un psicólogo de 29 años de edad, trabajó como coordinador de Mexfam en Cuajimalpa, una región de bajos ingresos en las afueras de Ciudad de México. "Los centros abrieron la puerta a una nueva generación”, dijo Zárate. "Organizaron actividades que les interesaban a los jóvenes y cultivaron un ambiente en el cual los adolescentes se sentían cómodos". Sin embargo, al poco tiempo quedó claro que el programa no estaba logrando sus objetivos. Aunque los centros resultaban útiles para los jóvenes que asistían, el número total de participantes era reducido y el costo promedio por jóven era muy alto.

En 1988 Mexfam realizó la primera evaluación de Gente Joven. La evaluación mostró que las actividades del programa beneficiaban a un grupo limitado de adolescentes, y que los que asistían a los centros ya tenían un alto nivel de motivación. Los jóvenes que más necesitaban servicios y educación no eran los que asistían a los centros. La evaluación también demostró que la información ofrecida por los centros estaba mal organizada y en muchos casos había sido improvisada de acuerdo a las circunstancias. Por último, quedó claro que para ampliar el alcance del programa sería necesario abrir más centros, y que el costo necesario (tanto en materiales como personal) sería muy alto.

Pero el resultado más notable de la primera evaluación de Gente Joven fue el perfil que presentó del comportamiento sexual de los adolescentes mexicanos. La evaluación mostró que la mayoría de los adolescentes sexualmente activos tienen relaciones sexuales sólo esporádicamente, por lo cual no consideran necesario usar métodos anticonceptivos más allá de condones o espermicidas. Esta información resultó útil porque el personal de Mexfam todavía no había decidido de si debían distribuir anticonceptivos entre adolescentes, y menos todavía cómo deberían hacerlo. Gracias a la evaluación, Mexfam decidió distribuir condones en los centros Gente Joven. Los adolescentes que indicaban tener relaciones sex- 
uales regularmente y deseaban usar otro tipo de anticonceptivo podrían ser derivados a las clínicas de planificación familiar de Mexfam. La evaluación también indicó que los jóvenes estaban más dispuestos a participar en el programa si se les ofrecía un rol activo con algún grado de responsabilidad.

El concepto para el programa actual de Gente Joven fue propuesto por Gabriela Rodríguez, directora de apoyo técnico de Mexfam. Una psicóloga con 14 años de experiencia en educación sexual, Rodríguez se integró a Mexfam en 1984, luego de trabajar para la Comisión Nacional de Población (CONAPO) como diseñadora del segmento educativo del Programa Nacional de Educación Sexual. Dentro de los programas de CONAPO, dice Gabriela, "la planificación familiar se entendía como educación sexual y servicios de salud reproductiva, y estos se entendían como parte de los servicios médicos generales y la distribución de anticonceptivos". En Mexfam, en vez de elaborar materiales para maestras, doctores y personal técnico, Gabriela empezó a trabajar directamente con el público recipiente de los servicios de Mexfam: los sectores más pobres de la población mexicana. Por primera vez, Rodríguez se involucró en la prestación de servicios de planificación familiar.

Rodríguez recuerda la sorpresa que sintió al ver que en Mexfam, "la planificación familiar se ubicaba en un contexto de servicios médicos y de distribución de anticonceptivos, y que estaba dirigida principalmente a mujeres que no deseaban tener más hijos". Desde una perspectiva de educación sexual, era evidente que este tipo de servicios de planificación familiar no beneficiaba mucho a los jóvenes. "Fue entonces que me empecé a interesar en la elaboración de una estrategia para adolescentes", dice Rodriguez. "Para mí, la planificación familiar representa un grupo de servicios de educación sexual y salud reproductiva que va más allá de los servicios médicos". Rodríguez decidió que para ser un programa de planificación familiar que le importara a los adolescentes, Gente Joven tendría que enfrentar el tema de la sexualidad directamente, con seriedad y franqueza.

Gente Joven también recibió mucha ayuda de José Aguilar, un médico y psicoanalista de Mexfam que participó activamente en la elaboración de la nueva estrategia y que actualmente funciona como coordinador del programa. Aguilar había trabajado previamente para el Centro de
Orientación para Adolescentes (CORA), una entidad sin fines de lucro donde también participó en la elaboración de programas para adolescentes. CORA mantiene varios centros para jóvenes en la Ciudad de México que ofrecen servicios de salud, programas educativos y distribución de anticonceptivos en la comunidad.

Rodríguez y Aguilar dedicaron cuatro meses al análisis de los resultados de la primera evaluación del programa. Luego de considerar las ventajas y desventajas de cada elemento del programa, empezaron a formular una estrategia con el propósito de responder a los problemas que habían identificado.

El primer paso habia sido abrir centros para jóvenes que ofrecian clases educativas y culturales, como ser teatro, ejercicio y baile, además de educación sexual y servicios clínicos. Fue muy lindo, porque venían unos 20 jóvenes por día que ayudaban con el trabajo, jugaban ping-pong $y$ conocían toda la información sobre sexualidad. Pero la realidad era que los centros no estaban creciendo. Durante casi un año los adolescentes que venían eran siempre los mismos. Empezamos a pensar que quizás deberíamos mandar a estos jóvenes a sus propias escuelas, acompañados por los coordinadores del programa, con el propósito de estimular discusiones sobre sexualidad. A esa altura la asistencia a los centros empezó a disminuir, y nos dimos cuenta que los jóvenes en realidad no tenían razones para regresar. Sus amigos, novios y novias estaban en otros sitios. Fue entonces que nos dimos cuenta que el trabajo de educación sexual no necesita un centro, y decidimos llevar el programa a los jóvenes.

Rodríguez y Aguilar decidieron que lo más importante sería ver y tratar a los adolescentes como tales, no como adultos, y reconocer las diferencias entre varones y mujeres. También decidieron que sería fundamental usar métodos que no fueran caros y generar indicadores cuantitativos y cualitativos que permitieran algún tipo de evaluación del programa. El primer gran cambio producido por la evaluación fue la decisión de cerrar los centros para adolescentes.

\section{Gente Joven en la actualidad}

Hoy Gente Joven busca a los jóvenes en los lugares que más frecuentan: las escuelas y colegios, los centros deportivos y recreativos, en el trabajo, la calle y otros sitios de encuentro. En 
vez de tratar de hacer que los jóvenes vengan a Mexfam, el programa ahora busca a los adolescentes en lugares donde ellos se congregan voluntariamente, lugares que reflejan su identidad y sus aspiraciones. Este enfoque reconoce el hecho de que la adolescencia, como dice Rodríguez, "es la etapa de vida en la que uno define lo que quiere ser". Mexfam también reconoce la importancia de alterar sus programas para alcanzar a grupos específicos de adolescentes, ya sean estudiantes, trabajadores o simplemente los que están en la calle.

El personal de Gente Joven consiste en coordinadores y promotores especialmente capacitados en la comunicación de información sobre la sexualidad a los adolescentes y provistos de materiales impresos e ilustraciones diseñadas específicamente para el programa. Los coordinadores son empleados permanentes de Mexfam, mientras que los promotores son voluntarios. En la actualidad Mexfam cuenta con 17 coordinadores dedicados exclusivamente a Gente Joven, los cuales supervisan a unos 1.573 promotores y facilitan la participación de 248 médicos comunitarios afiliados a Mexfam. Los coordinadores también organizan y llevan a cabo cursos y talleres para jóvenes.

Según el manual operativo de Gente Joven, un coordinador debe tener por lo menos 21 años, educación secundaria completa, y demostrar in- terés en los problemas de la juventud y los temas de sexualidad, embarazo adolescente y comunicación en la familia. Un coordinador debe además demostrar una actitud abierta hacia la diversidad de experiencias sexuales y reproductivas de la juventud contemporánea. Otros atributos indispensables incluyen una buena capacidad de comunicación con individuos y con la comunidad, una aptitud para dirigir discusiones en grupo, y la creatividad e iniciativa necesarias para atraer jovenes a las actividades de Gente Joven. Además de los 17 coordinadores exclusivos de Gente Joven, Mexfam capacita a sus otros coordinadores locales (los que supervisan todas las otras actividades de la organización) para que puedan incorporar las necesidades de los adolescentes en dichas actividades.

Todos los promotores de Gente Joven son voluntarios de entre 16 y 20 años de edad, y muchos son estudiantes de secundaria. Mexfam selecciona a los promotores en base a varias cualidades: una facilidad para establecer amistades en situaciones de grupo; entusiasmo; respeto hacia la perspectiva de otros; un demostrado interés en el bienestar de sus compañeros y en las inquietudes sexuales y reproductivas de la juventud; un sentido de compromiso y responsabilidad; y una capacidad para trabajar en un entorno comunitario y interpretar información científica de modo correcto.

Los promotores reciben capacitación bási-

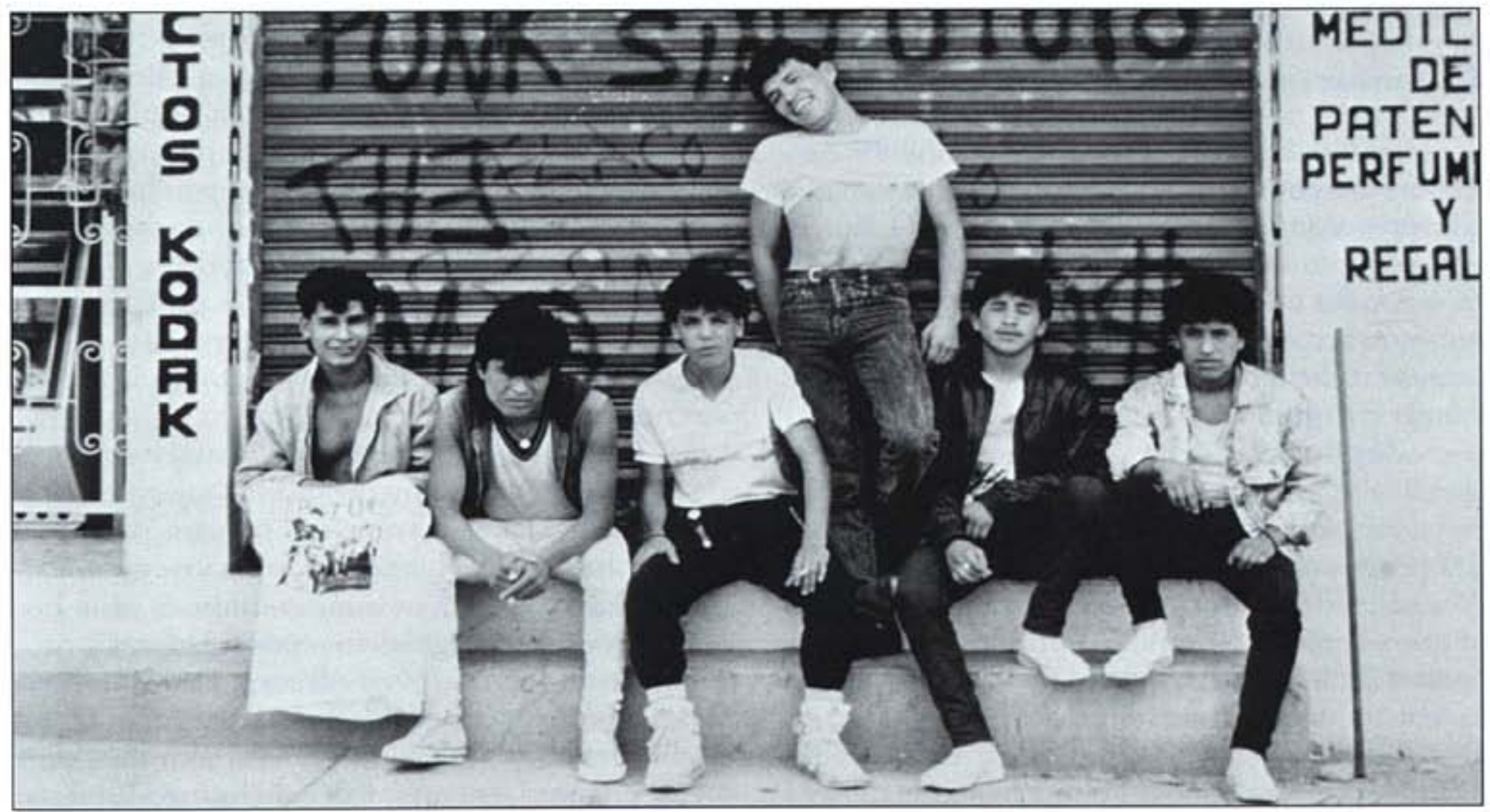


ca en todos los temas del programa. Mexfam también identifica a los promotores que demuestran una aptitud especial y les ofrece un programa de capacitación más detallado. Este programa está basado en el curso "Planeando tu vida", que fue desarrollado por Mexfam y el Instituto Mexicano de Investigación en Familia y Población. (4) Ese curso, a su vez, es una adaptación del Programa de Educación en Planificación de Vida, que fue elaborado por el Center for Population Options en base a la realidad social mexicana. El programa también incorpora materiales diseñados por Planned Parenthood de Bergen County, Nueva Jersey, E.E.U.U., Family Planning and Genetic Services de Texas, E.E.U.U., y técnicas desarrolladas por el personal de Gente Joven.

El programa de capacitación para promotores consiste de 14 sesiones. A los promotores que lo completan se les permite distribuir información y condones entre adolescentes. Los promotores también asisten a los coordinadores durante pláticas sobre educación sexual; así reciben experiencia práctica sobre lo que aprenden en el programa de capacitación.

El promotor típico ha demostrado interés en los temas abarcados por el programa y funciona como tal durante unos seis meses. Luego de este plazo la mayoría de los promotores se empiezan a separar del programa y seguir otros caminos, ya sea la universidad, un nuevo empleo u otra actividad.

\section{Comunicándose con jóvenes}

Además de la importancia de involucrar a los jóvenes como promotores, Rodríguez y Aguilar reconocieron desde el principio que Gente Joven necesitaría un medio especial de comunicación con los adolescentes. Las técnicas de comunicación normalmente utilizadas por Mexfam no eran necesariamente las más apropiadas para alcanzar a jóvenes.

$\mathrm{Al}$ principio lo más importante era asegurar que Gente Joven transmitiera información correcta y apropiada a los jóvenes. Pero los dirigentes del programa pronto se dieron cuenta de que el contenido de la información era menos importante que el modo en que se la comunicaba. Muchas comunidades a lo largo de México carecen de información sobre sexualidad, anticoncepción, enfermedades de transmisión sexual, etc. Entre los jóvenes es evidente además una marcada diferen- cia entre lo que conocen y lo que practican en lo personal. Muchos adolescentes demuestran conocimientos adecuados sobre algunos métodos anticonceptivos y sobre cómo evitar las enfermedades de transmisión sexual, pero muchos también admiten que no practican lo que saben.

Algunos estudios han indicado que esta brecha entre el conocimiento y la práctica tiene que ver con factores culturales, como ser el género, las presiones sociales, $y$ la falta de oportunidades educativas, políticas y profesionales-especialmente para mujeres. Pero según un informe sobre el embarazo entre adolescentes en América Latina y el Caribe, "también existen obstáculos estructurales para la obtención de anticonceptivos, obstáculos que reflejan las actitudes negativas que muchos padres y educadores guardan hacia la sexualidad en general y hacia los adolescentes en particular. Varios factores se combinan para impedir que los jovenes tomen ventaja de la anticoncepción: la falta de simpatía que los adolescentes perciben en los proveedores de servicios de planificación familiar (aunque sea una percepción incorrecta), el sentimiento de vergüenza y culpa que muchos jóvenes asocian con la sexualidad, y el temor de que sus padres se enteren de su comportamiento sexual". (5)

Para cambiar estas actitudes es necesario combinar información apropiada con métodos de comunicación apropiados. Los tradicionales folletos y manuales sobre sexualidad para jóvenes suelen limitarse a una descripción de anatomía reproductiva y procesos biológicos. Dichos materiales expresan una perspectiva adulta de la sexualidad: sexo como tema intelectual, artificialmente separado de cualquier contexto humano y emotivo. Pero los jóvenes suelen darle mucha importancia a los aspectos emocionales de cualquier situación. Así, es mucho más probable que asimilen información si ésta se presenta en un contexto de vida real que incluye todos los matices emotivos.

El programa Gente Joven actual es el fruto de un proceso contínuo de aprendizaje y revisión de los materiales, combinado con un profundo compromiso con el bienestar de los jóvenes mexicanos. El programa actual también es más homogéneo que el original: los coordinadores y promotores de Gente Joven ofrecen el mismo material básico en comunidades a lo largo de México. Sin embargo, en cada región los coordinadores añaden materiales especiales de interés local, en 


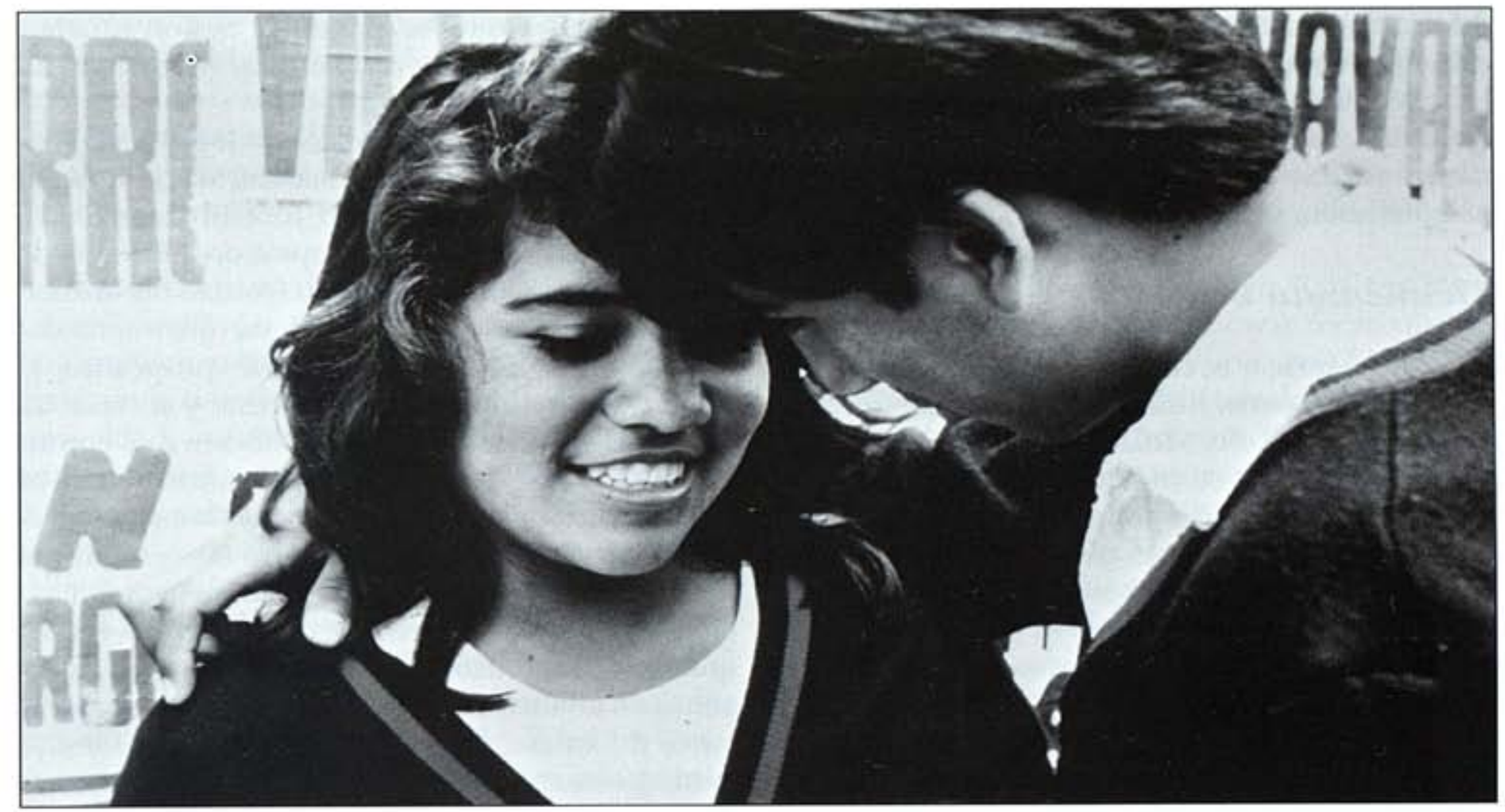

base a una evaluación de las necesidades de cada comunidad.

\section{El programa en escuelas y fábricas}

Los dirigentes de Gente Joven trabajan con maestros y profesores para ofrecer el programa en escuelas intermedias y secundarias y en universidades. Dada la naturaleza controversial de los materiales, los maestros reciben ejemplares por adelantado, y Mexfam propone que los maestros participen en las discusiones y encuentren maneras de integrarlas en el programa educativo general. Típicamente, Mexfam sugiere que las escuelas incorporen el programa de Gente Joven como un curso de diez horas en total, divididas en cinco sesiones de dos horas ofrecidas en cinco días consecutivos. Dado que cada sesión introduce la siguiente, este método resulta más efectivo que uno en que se presenta una sesión por semana. Un coordinador o promotor de Mexfam dirige las sesiones con el apoyo de maestros o profesores que desean establecer mejores lazos con sus estudiantes.

El director de nuestra escuela piensa que los cursos de Mexfam son muy importantes para la educación de los estudiantes. Nosotros ofrecemos los cursos para estudiantes de 13 y 14 años de edad al final de cada año. La sexualidad es una parte importante de la vida de los jóvenes. Con los cursos de
Mexfam nuestros estudiantes aprenden que la sexualidad no es el aspecto más importante de sus vidas, sino más bien sólo un aspecto, y así aprenden a manejar su sexualidad desde esa perspectiva.

Alicia Segura

Maestra

Cuajimalpa, México

Para alcanzar a jóvenes que trabajan, Gente Joven emplea una estrategia similar a la que utiliza con estudiantes, ofreciendo cursos sobre sexualidad y planificación familiar en fábricas pero enfatizando pláticas menos formales. Gente Joven no se limita a ofrecer información y distribuir anticonceptivos; más bien trata de estimular discusiones y análisis sobre dichos temas, con el propósito de estimular a los jóvenes a que tomen decisiones propias sobre su comportamiento sexual. Primero, los coordinadores de Mexfam establecen una relación con la gerencia de una fábrica y proponen ofrecer información sobre planificación familiar para los empleados. El contacto inicial suele hacerse con el médico residente que típicamente se encuentra en las fábricas industriales de México. Posteriormente el médico elige un horario para las pláticas, típicamente durante las horas de trabajo, y le avisa a los trabajadores. Antes de conducir una sesión, Mexfam analiza la composición de los empleados de la fábrica. Cuando la edad promedio de los trabaja- 
dores es entre 15 y 20 años, Mexfam ofrece básicamente el mismo curso que ofrece en las escuelas, excepto que para ilustrar conceptos se utilizan ejemplos más apropiados al entorno laboral. Si la fábrica no dispone de mucho tiempo para las pláticas, Mexfam ofrecen una versión condensada.

\section{Alcanzando a jóvenes en la calle}

En México, el fenómeno de la pandilla urbana se encuentra limitado principalmente a la capital, Ciudad de México. Así como en otras grandes ciudades, en México las pandillas surgen de la combinación de pobreza y el ambiente de violencia que es cada vez más común en los centros urbanos. Los miembros de pandillas típicamente son adolescentes que ni trabajan ni estudian. Estos jóvenes pasan la mayoría del tiempo en la calle y suelen participar en actividades ilegales que les ponen en conflicto con la policía.

Según Gabriela Rodríguez, es importante trabajar con las pandillas porque "muchos adolescentes en México comparten esas circunstancias: han dejado de asistir a la escuela y no tienen trabajo. Este grupo requiere una estrategia especial y más directa". A través de sus coordinadores y promotores, Mexfam ha logrado establecer contactos con miembros de varias pandillas. Una de las sorpresas para Mexfam fue descubrir que las pandillas atraen a jóvenes de am- bos sexos. Aunque las pandillas tienen muchos más varones que mujeres, las mujeres forman un grupo importante.

El trabajo con pandillas de Gente Joven comenzó en enero de 1991, cuando Mexfam firmó un acuerdo con el Consejo Juvenil Popular. El Consejo fue formado a principios de la década de los 80, cuando 30 pandillas en Ciudad de México se unieron en un intento de desarrollar actividades conjuntas. El Consejo tiene dos propósitos: 1) acabar los conflictos con la policía, y 2) realizar actividades educativas que beneficien a la comunidad. Con el apoyo económico de entidades en el sector privado, los fundadores del Consejo lograron construir y equipar un centro. Un comité de jóvenes elegidos por los grupos dirige la organización. El Consejo ofrece una gama de actividades que incluye servicios de asesoramiento legal, campañas de alfabetización, y apoyo a clubes comunitarios de karate, fútbol y básquetbol. El Consejo también organiza festivales de teatro, exhibiciones de pintura, pinturas murales y conciertos de rock conocidos como "tocadas". Además se ofrecen cursos en serigrafía, enfermería y cosmetología.

Muchos de los miembros de pandillas en México están en contra de los sistemas formales de educación y trabajo y de la organización general de la sociedad. Muchos de estos jóvenes rechazan los valores tradicionales impuestos por las autoridades. No obstante, muchas de las pandillas que

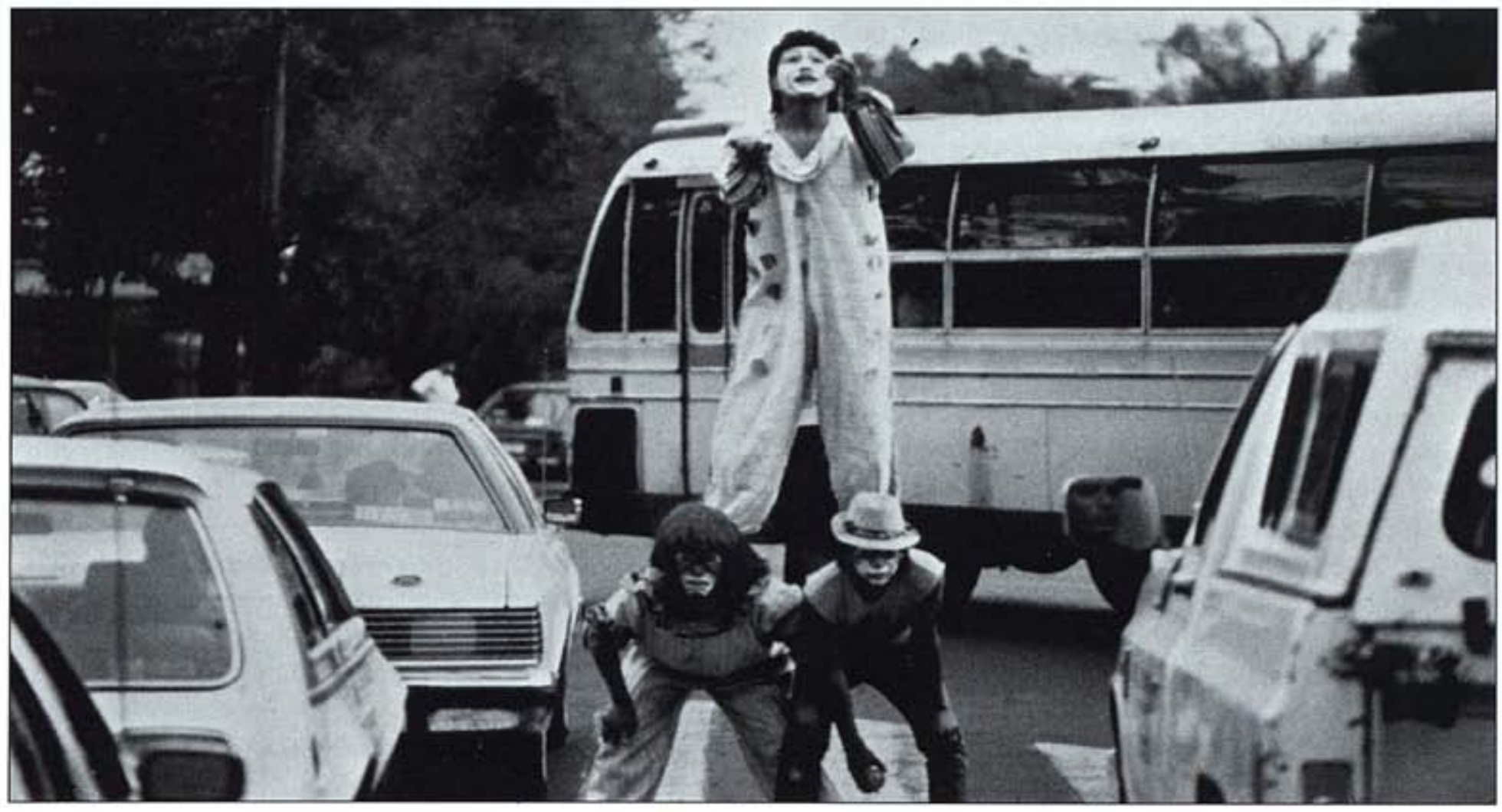


participan con el Consejo también han demostrado interés en el desarrollo de su propia "cultura" y en compartir sus propios valores con la comunidad. Para estas pandillas, el Consejo representa una manera de empezar a distanciarse de actividades ilegales y conflictos con la policía, sin tener que abandonar sus valores fundamentales.

Cuando los dirigentes del Consejo empezaron a trabajar con adolescentes, descubrieron una preocupante falta de información (así como un abundancia de información incorrecta) sobre sexualidad, enfermedades de transmisión sexual, anticoncepción y salud reproductiva. "Los muchachos y las muchachas que visitan nuestro centro no saben nada de sexualidad", dice Andrés Castellano, uno de los dirigentes del Consejo.

Conciente de esta realidad, Mexfam inició un proyecto, denominado "Chavos Banda", con el propósito de alcanzar y ganar la confianza de los miembros de pandillas. "Lo más difícil fue convencerlos que éramos diferentes, que sólo queríamos ayudarlos, y que no esperábamos nada a cambio", dice Carmen Leyte, la coordinadora del proyecto para Mexfam.

Tras una serie de discusiones, el Consejo Juvenil Popular decidió incorporar un programa comunitario de Mexfam en sus actividades. Mexfam adaptó una versión de sus cursos para escuelas y fábricas para los propósitos de "Chavos Banda". Mexfam también empezó a organizar talleres para dirigentes del Consejo donde se les ayuda a incorporar temas de sexualidad y salud reproductiva en las actividades programadas del Consejo.

El trabajo con pandillas fue un paso importante para Gente Joven. Gabriela Rodríguez dice que "con pandillas la estrategia debe ser diferente. Estos jóvenes no están en las aulas, están en la calle. Los que están afiliados al Consejo hacen música, teatro, organizan charlas, y es ahí donde empiezan a introducir el tema de la sexualidad". Cuando las pandillas organizan teatro en la calle, por ejemplo, Mexfam suele discutir los temas de Gente Joven con los libretistas, actores y productores, ya que todos son jóvenes miembros de pandillas. Dichos temas luego suelen aparecer en algún aspecto de las producciones, que como todos los proyectos de teatro del Consejo, tienen como propósito generar discusión entre los miembros del público, ya sean niños, ancianos, padres o adolescentes. En vez de decirles a los adolescentes cómo deben comportarse, Gente Joven trata de mostrar varias opciones en la expresión de la sexualidad. Los mensajes del programa reconocen las motivaciones sexuales que los adolescentes sienten y les ayudan a comprender las consecuencias de distintas prácticas sexuales. Además se discute cómo evitar situaciones como el embarazo no deseado y las enfermedades de transmisión sexual.

Los resultados del proyecto "Chavos Banda" han sido mucho más positivos de lo que se esperaba. Durante el primer año de actividad, el proyecto ofreció educación sexual a 2.500 adolescentes y 380 padres. Además, 150 psicólogos, trabajadores sociales y maestros fueron capacitados como promotores del programa. También durante el primer año Mexfam donó el equipo necesario para abrir la primer clínica en el centro del Consejo. En el curso de serigrafía, los jóvenes diseñaron playeras que combinaban el logotipo de Mexfam con el del Consejo y promovían el uso de condones, mientras que otros pandilleros pintaron murales con mensajes educativos sobre sexualidad y salud reproductiva.

\section{La ventaja de la radio}

Teniendo en cuenta el impacto y alcance de la radio, Mexfam decidió añadir este medio a las opciones de difusión para los mensajes de Gente Joven. Mexfam creó un programa, "Estrenando Cuerpo", que combina humor, música moderna (especialmente rock y disco) y orientación sexual para jóvenes de entre 11 y 21 años de edad. El programa ofrece información, comentarios y criterios para tomar decisiones relativas a sexualidad, planificación familiar y salud. Otros temas son cómo mejorar la comunicación con padres y amigos y el papel que el afecto juega en las relaciones humanas, y especialmente en las sexuales. Temas específicos incluyen el cuerpo, la sexualidad de los padres, roles sexuales, homosexualidad, machismo, madres adolescentes, depresión y tristeza, mitos sexuales, nutrición, imaginación, amor platónico, divorcio y ansiedades. Mexfam ha producido más de 100 programas distintos de 25 minutos cada uno. Los programas ofrecen un tratamiento completo de un tema y pueden ser emitidos en cualquier orden; las estaciones de radio los pueden repetir cuantas veces quieran.

"Estrenando Cuerpo" fue producido por Mexfam y Radio Educación, la estación oficial del Ministerio de Educación Pública de México. Unas 67 estaciones de radio en todo el país han emiti- 
do los programas, y los resultados en términos de público alcanzado han sido óptimos. "Estrenando Cuerpo" fue premiado por el Instituto de Población de México en 1991 como el mejor programa sobre el tema en todo el país.

\section{El curso de educación sexual}

El primer paso en el desarrollo de Gente Joven fue la formulación de un programa de capacitación en educación sexual para los coordinadores de Mexfam. Bajo la supervisión de Gabriela Rodríguez, Mexfam creó un programa de 30 horas de duración que definió los requerimientos mínimos para que un coordinador participara en el programa.

El curso de capacitación para coordinadores incluye análisis y discusión de 16 temas: sexo y sexualidad; sexualidad y la familia; sexualidad y los medios; sexualidad y valores; roles sexuales; sexualidad entre niños; pubertad y adolescencia; sexualidad entre jóvenes; embarazos no deseados en la adolescencia; relaciones personales; reacción sexual humana; disfunción sexual; enfermedades de transmisión sexual/SIDA; perfil de un educador sexual; y el programa de Gente Joven en sí.

El curso fue diseñado para estimular una revisión del punto de vista del coordinador a través de un proceso de crítica y análisis. En la primera parte del curso se analizan los valores y la perspectiva del participante hacia la sexualidad, y especialmente hacia la sexualidad de los adolescentes. El objetivo es comunicar información en el contexto de despertar en los participantes conciencia de sus propias percepciones y su comportamiento sexual. En la primera parte del curso, se anima a los participantes a analizar cómo sienten y qué creen con respecto a la sexualidad. En la segunda parte, los participantes aprenden a poner de lado sus propios valores para poder apreciar y respetar otra perspectiva, en este caso la de los jóvenes, sin imponer sus propias preferencias.

El objetivo del curso es producir coordinadores capaces de escuchar a los adolescentes, respetar sus valores, proveerles con información imparcial y correcta, y ayudarles a tomar decisiones según sus propias necesidades. En México, como en muchos países, la sexualidad se suele entender en términos negativos, como un instinto primitivo o una fuerza inmoral que debe ser reprimida y controlada. Gente Joven trata de pre- sentar la sexualidad como un aspecto positivo de la vida. El propósito principal del programa consiste en comunicar el hecho de que el sexo se puede disfrutar de un modo seguro, saludable y responsable.

Mexfam trata de crear oportunidades para que los coordinadores en distintas partes del país puedan reunirse para compartir ideas, problemas y experiencias. Dos veces por año todos los coordinadores y supervisores del programa se reúnen con el personal superior de la sede central de Mexfam, y por lo menos una vez por año los coordinadores reciben cursos de capacitación para actualizar sus conocimientos.

El próximo paso en el desarrollo del programa para Gente Joven fue preparar un curso sobre sexualidad para jóvenes. Mexfam decidió organizar el curso en torno a cinco temas. Los temas fueron elegidos en base a varios estudios que buscaron identificar las principales preocupaciones de los jóvenes. Uno de los problemas más comunes, por ejemplo, resultó ser la falta de comunicación entre adolescentes y padres. Un estudio sobre jóvenes en Ciudad de México concluyó, además, que "la definición de educación sexual debe ser ampliada y requiere un importante enfoque en la familia si se han de prevenir embarazos no deseados y enfermedades de transmisión sexual. Es preciso diseñar estrategias que promuevan un intercambio claro y abierto entre padres y jóvenes". (6) Como resultado, se decidió que los cinco temas del curso serían: comunicación entre adolescentes y sus familias; pubertad y el proceso de vida; sexualidad y juventud; las enfermedades de transmisión sexual y su prevención; embarazo precoz y métodos anticonceptivos.

Primera sesión. Comunicación entre adolescentes y sus familias. Los conceptos básicos tratados por esta sesión son: comunicación (es decir, comunicación dentro de la familia entendida como un proceso continuo de emisión y recepción de mensajes); expresiones utilizadas en la comunicación (como ser sonidos, silencios, tonos de voz, llanto, lenguage verbal y físico); la familia y los distintos estilos de comunicación familiar (la familia rígida, la familia demasiado protectora, la familia inestable, la familia que trata de evitar conflictos, la familia encabezada por un solo padre); y métodos para mejorar la comunicación. Se trata de motivar a los partici- 
pantes para que definan sus propios valores y mejoren el nivel de comunicación con sus propios padres. En esta sesión también se habla de cómo obtener información correcta sobre sexualidad, reproducción humana, prevención de enfermedades de transmisión sexual y métodos anticonceptivos.

Segunda sesión. Pubertad y proceso de vida. El facilitador de la sesión ofrece una introducción general sobre los cambios en el cuerpo a lo largo de la vida y explica la anatomía reproductiva de ambos sexos en detalle. Tanto el facilitador como los materiales de Gente Joven emplean un vocabulario simple y directo, evitando el uso de explicaciones demasiado científicas sobre los órganos reproductivos y sus funciones. Esta sesión también sirve para clarificar algunos de los mitos mexicanos más comunes sobre la pubertad (como ser la idea de que las muchachas no deben bañarse o hacer ejercicios durante la menstruación y que los besos pueden causar un embarazo).

Tercera sesión. Sexualidad y juventud. Esta sesión ofrece una oportunidad para que los participantes discutan sus opiniones sobre sexualidad y las normas culturales que gobiernan el comportamiento de niños y niñas, hombres y mujeres. El facilitador explica los mecanismos de la excitación sexual y las relaciones sexuales. También se habla sobre abstinencia, masturbación, prostitución y pornografía. Al concluir esta sesión el facilitador introduce la imagen de una balanza, proponiendo que los jóvenes pueden analizar las ventajas y desventajas de cada situación antes de actuar, y enfatizando la capacidad de decisión que los participantes tienen sobre sus vidas.

Cuarta sesión. Enfermedades de transmisión sexual. Esta sesión se encarga de definir las ETS, cómo se transmiten, los síntomas más comunes y los métodos de prevención y tratamiento, además de la transmisión del Virus de Inmunodeficiencia Humana (VIH) y la prevención del SIDA.

Quinta sesión. Embarazo precoz y anticoncepción. El facilitador repasa los aspectos culturales del embarazo y el uso de anticonceptivos y ofrece información médica y estadística. Con la ayuda de películas y videos, el facilitador habla sobre cómo un embarazo no deseado puede cambiar la vida de un adolescente, interrumpiendo sus estudios y perjudicando su futuro. Parte de la sesión se dedica a las principales ventajas y desventajas de los métodos anticonceptivos más co- munes. Al concluir, la sesión vuelve a subrayar la importancia de las decisiones basadas en valores propios y el reconocimiento de las opciones que cada adolescente tiene en cuanto a su comportamiento sexual.

Mexfam preparó un manual para coordinadores y promotores que explica cómo ampliar cada tema y adaptarse a situaciones especiales o problemáticas. Mexfam también provee folletos sobre cada tema para repartir entre jóvenes. Por lo general se utilizan medios audiovisuales para generar discusiones; para situaciones donde no existe la infraestructura para dichos métodos, el programa ha desarrollado cinco ejercicios para discusiones de grupo que sirven como reemplazo.

El facilitador comienza cada sesión con una introducción y breves comentarios sobre el video u otros materiales que se están por presentar. Mexfam provee instrucciones específicas para la conducción de la discusión. Al concluir cada sesión el facilitador introduce el tema programado para la sesión siguiente y busca establecer una continuidad temática entre las sesiones. Gente Joven ha desarrollado una variedad de materiales de comunicación (videos, películas y folletos) específicamente para estimular discusiones entre los jóvenes.

\section{Los videos}

El video es uno de los medios más eficaces para comunicar mensajes complejos. Utilizados como parte de un curso específico y acompañados con materiales impresos, los videos permiten contextualizar la información en situaciones de vida real que ilustran las dimensiones emocionales del tema. Además, los videos representan un medio que muchos jóvenes asocian con la televisión, por lo cual tienen muchos más impacto que libros y otros materiales impresos tradicionalmente utilizados en la educación. Con el apoyo de la Organización Japonesa para la Cooperación Internacional en Planificación Familiar, Mexfam ha elaborado una serie de películas y videos cuyo propósito es estimular discusiones sobre sexualidad. Los videos reflejan los entornos urbanos y rurales de México. Dado el sentimiento de vergüenza que suele acompañar las discusiones sobre el sexo, los videos tienen la ventaja de poder presentar temas delicados mediante imágenes que 


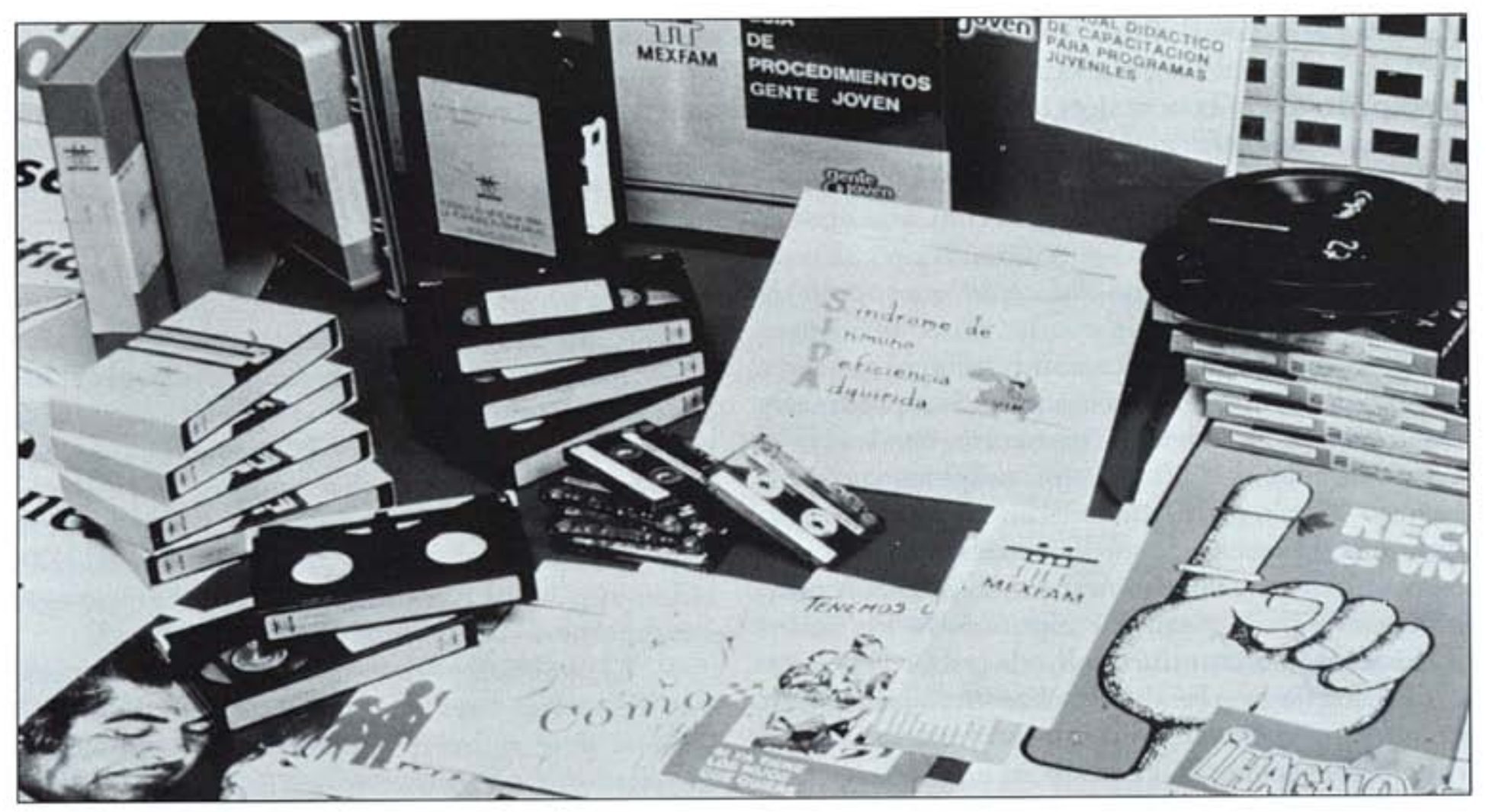

no requieren "explicación", pero que a la vez sirven para estimular discusiones.

Obviamente, las imágenes y el lenguaje utilizado en los videos debe ser elegido cuidadosamente para transmitir el mensaje deseado. Mexfam eligió utilizar el vocabulario popular de la juventud mexicana, sin caer demasiado en modismos o jergas de un grupo particular. Cuesta mucho producir un video, y si el lenguaje de la narración no es apropiado, se corre el riesgo de que el producto final sólo sea aplicable para un público limitado y deje de tener vigencia demasiado pronto. Es evidente, por ejemplo, que un video diseñado especialmente para jóvenes de zonas urbanas marginales probablemente no va a tener mucha repercusión entre jóvenes de una región rural.

Mexfam encontró una solución a este problema en el uso de dibujos animados sin narración verbal. Un ejemplo es "La Paloma Azul”, un dibujo animado producido para adolescentes de 10 a 15 años de edad que demuestra cómo un muchacho empieza a tener fantasías sobre una muchacha algo mayor que está dirigiendo una actividad de grupo. La historia no ofrece una conclusión y no especula sobre las consecuencias futuras de la situación. El propósito del video es estimular la imaginación y la discusión en la audiencia, abriendo paso a la asimilación de infor- mación provista por el programa. Después de pasar el video, el promotor le pregunta a los adolescentes cómo piensan que la historia termina, cómo piensan que terminaría alguna situación similar, y cómo se hubieran comportado si les tocara a ellos.

"Música para Dos", un dibujo animado más reciente, fue pensado para adolescentes de 15 a 19 años. Este video relata las dificultades de una muchacha que tiene experiencias negativas con dos muchachos antes de elegir como novio a un joven vecino que toca el saxofón y está dispuesto a usar condones. "Música para Dos" abarca muchos temas de importancia para los jóvenes: relaciones interpersonales, el rechazo, las modas, los estereotipos (uno de los muchachos anda en motocicleta) y los valores. La historia crea un ambiente ideal para que los jóvenes puedan expresar sus dudas y preocupaciones sobre el sexo, y facilita la presentación de información en temas sobre los cuales los adolescentes no se sienten muy seguros.

En una discusión posterior a la presentación de "Música para Dos" en una escuela secundaria en la ciudad de Querétaro, el promotor le pidió a los adolescentes que expresaran cómo habían interpretado la historia. El promotor solicitó respuestas a varias preguntas, como ser: ¿Por qué eligió la protagonista a su novio, en vez de los otros dos muchachos? ¿por qué no le gustaron los otros 
dos? ¿qué tipos de pensamientos y emociones sintió la protagonista? ¿estaban de acuerdo los participantes con su decisión? ¿por qué?

Al principio los jóvenes se mostraron tímidos, pero al rato se empezaron a identificar con la situación presentada en el video y a expresar sus opiniones, sus dudas, y sus temores. Uno de los estudiantes opinó que la protagonista del video tenía miedo de contraer una enfermedad de transmisión sexual, mientras que una de las muchachas opinó que la protagonista estaba buscando un hombre comprensivo, capaz de entender la importancia de utilizar condones.

Los estudiantes expresaron opiniones variadas, algunas de las cuales surgían de información incompleta que el promotor trató de clarificar. El tema de los condones, por ejemplo, provocó una variedad de reacciones entre los jóvenes. Muchos todavía piensan que el usar condones o no es una medida del afecto de la persona o el nivel de su compromiso en la relación, y frecuentemente el tema de los condones y la protección que brindan está entremezclado con sentimientos y actitudes hacia la sexualidad y el afecto.

A medida que continuó la discusión, los estudiantes fueron más allá del video y hablaron sobre situaciones imaginarias, pero $\sin$ perder de vista el tema general de la sesión. Empezaron a referirse al contexto de la historia del video con la frase "A mí, si me ocurriera eso..." A esa altura el video había logrado funcionar como un punto de partida, un territorio común, y un esquema de referencias contra el cual los participantes podían medir sus propias presuposiciones e interpretaciones.

Un nuevo video, "Los Mejores Deseos", completa lo que Mexfam denomina su trilogía de dibujos animados silenciosos. El enfoque de este video es la comunicación entre Sara y Gaspar, un joven matrimonio que vive con la familia de Sara por falta de recursos económicos. La historia trata las dificultades resultantes de la falta de privacidad, los problemas de comunicación, los deseos y las fantasías de los protagonistas y sus problemas económicos en el contexto cultural mexicano.

Mexfam ha producido un total de 16 películas en video y 3 dibujos animados para Gente Joven. En los próximos años Mexfam quiere producir menos videos y concentrar sus esfuerzos en la promoción de los que ya tiene y la investigación de nuevas maneras de utilizarlos.

\section{Incluyendo la perspectiva de los jóvenes}

La producción de un video para Gente Joven comienza con una evaluación de la necesidad de los temas a tratar, un análisis del vocabulario empleado en el guión y varias decisiones en cuanto a los conceptos que se tratará de comunicar. Pero el aspecto más importante de la producción es la participación de jóvenes. Antes de decidir sobre la versión final de un video, Mexfam muestra la primera versión a un grupo de adolescentes para conocer sus reacciones y comentarios. Mexfam luego modifica el video y repite el proceso varias veces, hasta que el producto final refleja el punto de vista de los jóvenes.

Un interesante ejemplo de este proceso ocurrió con "El último tren", una película de $16 \mathrm{~mm}$ a todo color sobre una joven pareja de clase obrera que vive en un sector urbano marginado. En la versión original de Mexfam, la muchacha está esperando a su novio en una estación de tren. Los dos han decidido fugarse ese día y empezar una vida juntos, dado que la muchacha está embarazada y no ha podido decírselo a sus padres. En el final de la película, los dos se encuentran en la estación y se van juntos. Mexfam pensó que el final mostraba un poderoso mensaje, dos adolescentes que dejaban la escuela y sus familias y se escapaban para empezar una familia sin conocer los peligros y las dificultades que les esperaban.

Desde la perspectiva adulta de los productores de Mexfam, parecía suficiente mostrar que la pareja había optado por un plan lleno de dificultades y peligro. Sin embargo, los adolescentes que vieron esta versión de la película dijeron que el final no encajaba con la realidad. Para los jóvenes, lo más probable era que la muchacha se quedara esperando en la estación porque el muchacho la abandona. Mexfam aceptó esta sugerencia, y la conclusión de "El último tren" ahora muestra cómo la madre del muchacho lo detiene mientras éste está preparando sus valijas para ir a la estación. En la pelea que sigue, la madre le dice que la muchacha no lo merece, que ella probablemente se ha acostado con varios muchachos. La madre le hace recordar al muchacho que todavía tiene toda la vida por delante. $\mathrm{Al}$ principio el muchacho sigue determinado, pero poco a poco va cambiando de parecer. Luego que la madre le repite que todavía es muy joven y le asegura que va a conocer a una muchacha mejor, el mucha- 
cho decide no ir a la estación. En la versión final de la película, la muchacha espera durante horas en la estación y finalmente toma el tren sola.

La inclusión de las perspectivas de adolescentes en los materiales de Gente Joven enriquece las discusiones y permite que los participantes consideren sus propios valores y sus propias decisiones. Para Mexfam, la participación de jóvenes en la producción del programa permite asegurar que el mensaje apropiado va a ser transmitido de un modo comprensible y eficaz.

\section{Diferencias entre muchachos y muchachas}

La producción de "El último tren", fue también una oportunidad para que Mexfam enfrentara directamente las cuestiones de género e identidad. A medida que Gente Joven ha crecido, los directores y coordinadores han elaborado su propia interpretación de cómo las diferencias entre las necesidades de hombres y mujeres, las percepciones y el poder afectan la conducta sexual y la planificación de la vida.

La sexualidad afecta a muchachas y muchachos de modos muy distintos. Esto se debe no sólo a las diferencias anatómicas, sino también a los distintos roles culturales asociados con el género. Los dirigentes de Gente Joven han concluido que el género es el factor que más influye en la brecha entre los conocimientos y la práctica de anticoncepción y sexo con protección.

Por ejemplo, cuando Gente Joven realizó un estudio sobre la prevención del SIDA entre adolescentes, la diferencia entre las actitudes de mujeres y varones en cuanto al uso de condones quedaron claras. Según Gabriela Rodríguez, "Las muchachas dicen que si un varón usa condones es porque quiere a su pareja, la quiere cuidar, y no quiere que quede embarazada. El SIDA no les preocupa. Por otro lado también piensan que el varón dispuesto a usar condones es uno que no se quiere comprometer, que sólo busca una aventura. La mayoría de las muchachas prefieren no hablar del condón con sus parejas porque no quieren dar la impresión de que tienen demasiada experiencia sexual; dicen que no queda bien hablar de condones".

En gran medida, los adolescentes de hoy continúan debatiéndose entre dos estereotipos de mujer en conflicto: la decente o la indecente, la madre o la prostituta. Las dudas y los temores que los adolescentes expresan muestran que es muy difícil contrarrestar las diferentes presiones, los mensajes contradictorios que reciben, y su propia falta de comprensión de la sexualidad. No sólo sienten que no pueden hablar de estos asuntos con los adultos, sino que tienen miedo también de hablar entre sí sobre la sexualidad. Como dice Rodríguez, "Es una situación angustiante; nos

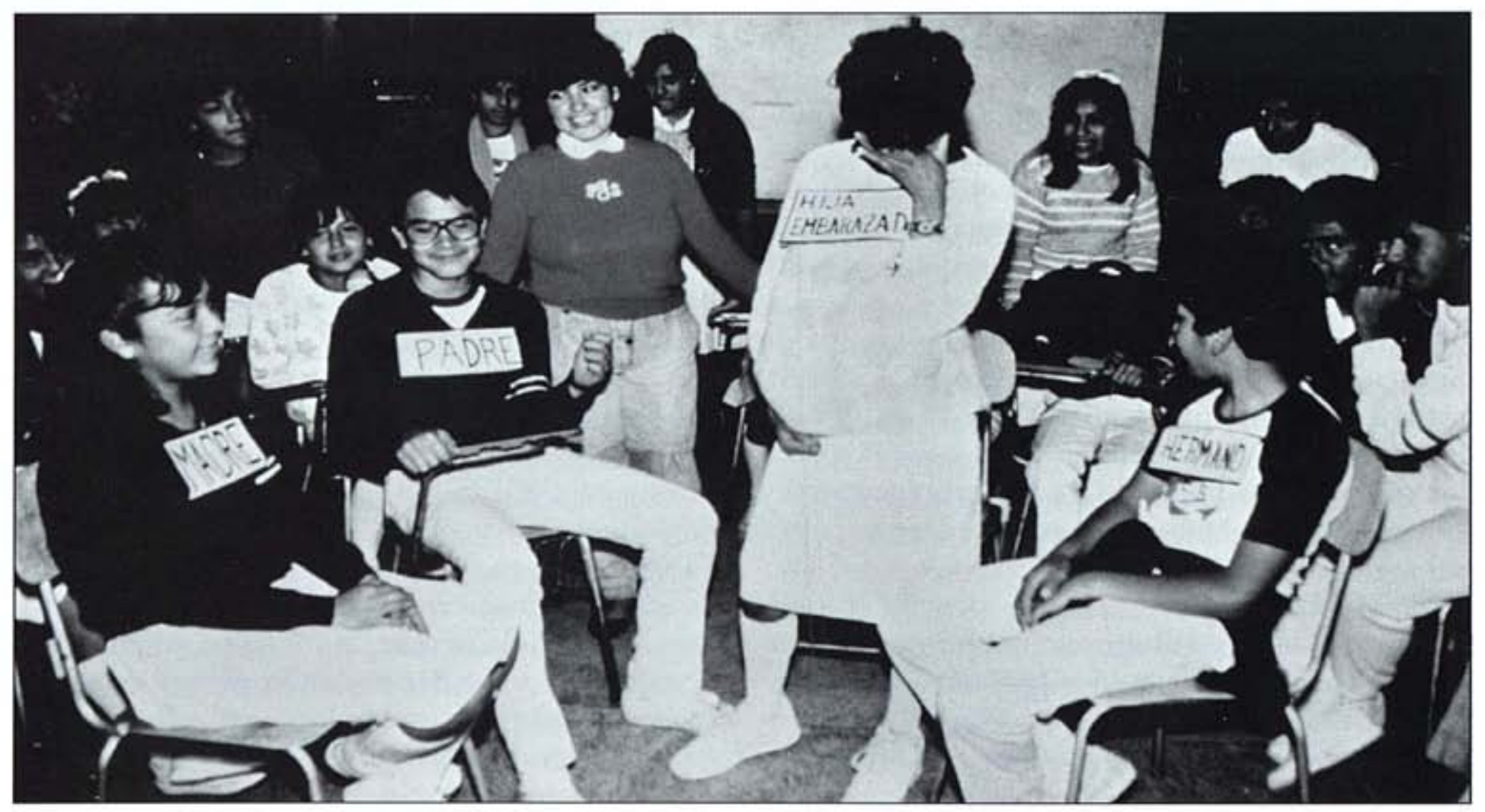


dimos cuenta que especialmente cuando se trata de la prevención del SIDA, es importante encarar las dinámicas de género que subyacen en estos problemas de comunicación. Los adolescentes conocen todas las medidas de prevención del SIDA al pie de la letra, pero otros factores, como ser el género, intervienen e impiden que los jóvenes actúen en base a lo que saben".

Gente Joven encaró el tema del género gracias principalmente a la inspiración e iniciativa de varias jóvenes mujeres mexicanas. Uno de los proyectos más interesantes en este sentido fue un grupo femenino de teatro, "Las Cucas", iniciado en el Consejo Juvenil Popular. Magdalena, una muchacha de 22 años de edad que integra el grupo, dice que "en general los temas relativos a la sexualidad femenina reciben muy poca atención, por lo cual en nuestra obras tratamos temas como la masturbación femenina, la violación, el embarazo, y el modo cómo se representa a las mujeres en revistas populares". Con la ayuda de Mexfam, "Las Cucas" produjo "El cielo o la cama", una obra en que la joven protagonista solicita la opinión de padres y amigos cuando su novio le pide que se entregue sexualmente. La obra no ofrece una respuesta concreta, pero sí presenta varios puntos de vista que ilustran la gama de presiones sociales que las muchachas deben negociar al decidir su comportamiento sexual.

Mexfam también convocó varios grupos de enfoque para aprender más sobre el efecto del género en la formación de valores y el proceso de decisión entre jóvenes. Luego de ver el video "Los mejores deseos", por ejemplo, un grupo de adolescentes fue dividido entre varones y mujeres con el propósito de discutir el relato. A cada grupo se le pidió analizar los siguentes aspectos de la historia: 1) la posibilidad de apoyar el desarrollo individual de tanto la mujer como el hombre en una relación; 2) la importancia de la colaboración en las tareas de mantenimiento del hogar y la generación de ingresos; 3) la división de las tareas domésticas y la distribución de recursos y poder entre el varón y la mujer; 4) la importancia de postergar el primer embarazo hasta que la pareja esté bien acostumbrada a vivir juntos.

La discusión demostró que los muchachos y las muchachas reaccionaron de forma distinta a cuestiones como el cuidado de niños, trabajo fuera del hogar, uso de anticonceptivos, comunicación y desarrollo del individuo. La mayoría de los varones opinaron que estaba bien que la mu- jer trabajara fuera del hogar, diciendo que "Gaspar debería dejar que Sara lo ayude", ya que los dos son responsables por su situación económica. También dijeron que "si el hombre no gana lo suficiente como para sostener a los dos, entonces tiene que permitir que la mujer trabaje". Sin embargo, muchos de los varones también opinaron que si la pareja tiene hijos, la mujer debe quedarse en casa para cuidarlos. Las muchachas, por otro lado, opinaron que "los muchachos temen que las mujeres van a formar amistades con otros varones si salen a trabajar", y que "no quieren que las mujeres ganen más que ellos". Las muchachas dijeron que "como cualquier mujer, Sara quiere ser más que ama de casa, se quiere desarrollar a sí misma". En cuanto a los deseos y las fantasías de Gaspar, los muchachos estaban de acuerdo que "la fantasía de los varones siempre es andar con otra mujer". En cuanto a la comunicación, a los muchachos les pareció importante que en el video "de alguna manera, tanto Gaspar como Sara reconocen sus errores". Las muchachas opinaron que "cada uno debe tener y expresar sus propias opiniones y permitir que el otro también las exprese".

Mexfam considera importante analizar las reacciones de los varones y las mujeres porque estas cuestiones "culturales" influyen en las actitudes sobre sexualidad y el uso de anticonceptivos. Las muchachas y los muchachos en el ejemplo anterior parecían estar de acuerdo en cuanto a la mayoría de los temas discutidos. Por ejemplo, ambos grupos mencionaron la importancia de postergar el primer embarazo y usar anticonceptivos "para poder llegar a conocerse mejor y disfrutar de su relación antes de tener hijos, como Gaspar y Sara que usan la píldora y también podrían usar condones". Sin embargo, es evidente que los roles basados en el género determinan los valores y los hábitos de comunicación de muchas parejas, y que estos factores pueden interferir con el manejo de la sexualidad. Mexfam cree que para cambiar las actitudes sobre sexualidad es necesario evaluar tanto los roles basados en género como los valores culturales.

Mexfam está tratando de introducir en los cursos de capacitación de Gente Joven esta conciencia de la relación entre el género y el modo en que los adolescentes ven y expresan la sexualidad. En la actualidad los cursos se dictan a grupos de entre 30 y 60 muchachas y muchachos. La inclusión de varones y mujeres en el mismo gru- 
po de capacitación fue a propósito. Como dice Rodríguez, "Nuestra impresión es que la comunicación entre hombres y mujeres es muy limitada. Los varones hablan entre sí y lo mismo hacen las mujeres, pero cuando les pedimos que hablen en pareja, ya sea sobre prevención o antes de hacer el amor, es como si les estuviéramos pidiendo algo imposible. Por eso es que decidimos específicamente que trataríamos de estimular discusiones en grupos mixtos, porque pensamos que es importante que los varones y las mujeres traten estos temas juntos. Queremos facilitar la comunicación para promover un diálogo mejor. Puede ser que las muchachas y los muchachos se sientan incómodos durante la discusión, pero por lo menos habrán hablado un poco más de lo que normalmente lo hacen. Es un comienzo".

Rodríguez también reconoce que "La perspectiva de género es algo nuevo que estamos empezando a introducir en el programa. Recién nos empezamos a capacitar en el análisis de género, pero ya reconocemos que podemos y debemos añadir una perspectiva de género de manera sistemática”.

\section{Los adultos suelen oponerse a la educación sexual}

Uno de los obstáculos que comúnmente encuentran los programas de educación sexual es la oposición de padres y otros adultos. Afortunadamente, este no fue un problema serio para Gente Joven. Sin embargo, Rodríguez dice que, "Obviamente, hay quienes se han opuesto al programa porque suponen incorrectamente que la educación sexual favorece la actividad sexual precoz y la promiscuidad entre los jóvenes. Es por eso que Mexfam le está dando más atención a la concientización de adultos, especialmente padres y directores de escuelas. Aunque hay cada vez más escuelas que aceptan Gente Joven, algunas todavía no nos permiten entrar".

En algunas comunidades los padres han solicitado más información sobre el programa porque lo ven como una manera de mejorar la relación con sus hijos adolescentes y entender mejor los cambios que éstos están experimentando. Para muchos padres, el programa también representa una oportunidad para aprender sobre anticoncepción. Tal fue el caso con un grupo de padres en la comunidad mexicana de Cuajimalpa. Al saber que sus hijos estaban recibiendo infor- mación sobre educación sexual a través de Gente Joven, los padres solicitaron información sobre el programa. Como resultado, un coordinador de Mexfam organizó un grupo de 12 padres dispuestos a reunirse de noche en el hogar de uno de los participantes. Los padres recibieron exactamente el mismo curso de educación sexual que Gente Joven le daba a sus hijos adolescentes en la escuela, incluso los videos y otros materiales. Con el apoyo del coordinador, los padres también pudieron discutir los temas del curso, lo cual les ayudó a comprender mejor las preocupaciones de sus hijos y cómo podrían ayudarles. La principal preocupación de casi todos los padres era el embarazo precoz, dado que ya habían visto varios casos en sus barrios. Los padres estaban especialmente preocupados sobre las consecuencias que dichos embarazos podrían tener para sus hijas, ya fuera la interrupción de sus estudios, la responsabilidad del cuidado de la criatura, la frecuente ocurrencia de un segundo embarazo precoz, o la eliminación de oportunidades profesionales.

Mexfam no le pide permiso a los padres de adolescentes antes de ofrecer Gente Joven porque esto sólo resultaría en demoras. La experiencia hasta ahora indica que la gran mayoría de los padres no se oponen al programa. Al contrario, muchos padres se sienten aliviados al saber que sus hijos están recibiendo algún tipo de información sobre sexualidad, por ser este un tema que a muchos padres les cuesta discutir con sus hijos.

\section{Distribución de anticonceptivos}

Desde la perspectiva adulta, unos de los aspectos más controversiales de un programa como Gente Joven es proveer anticonceptivos a adolescentes solteros. Muchos adultos creen que el acceso de adolescentes a los anticonceptivos promueve la promiscuidad. Algunos padres creen que sus hijos no piensan ni participan en relaciones sexuales si se los deja estar, pero que "caen" ni bien se los expone a información sobre el sexo, o peor aún, a anticonceptivos. En todo el mundo los adultos tienden a culpar a los programas de educación sexual por la ocurrencia del sexo y los embarazos entre adolescentes, en vez de reconocer que los jóvenes tienen un interés natural en el sexo y que al ofrecerles información, la educación sexual efectivamente les ayuda a tomar decisiones concientes. Mexfam tuvo en cuenta la posibilidad de una reac- 


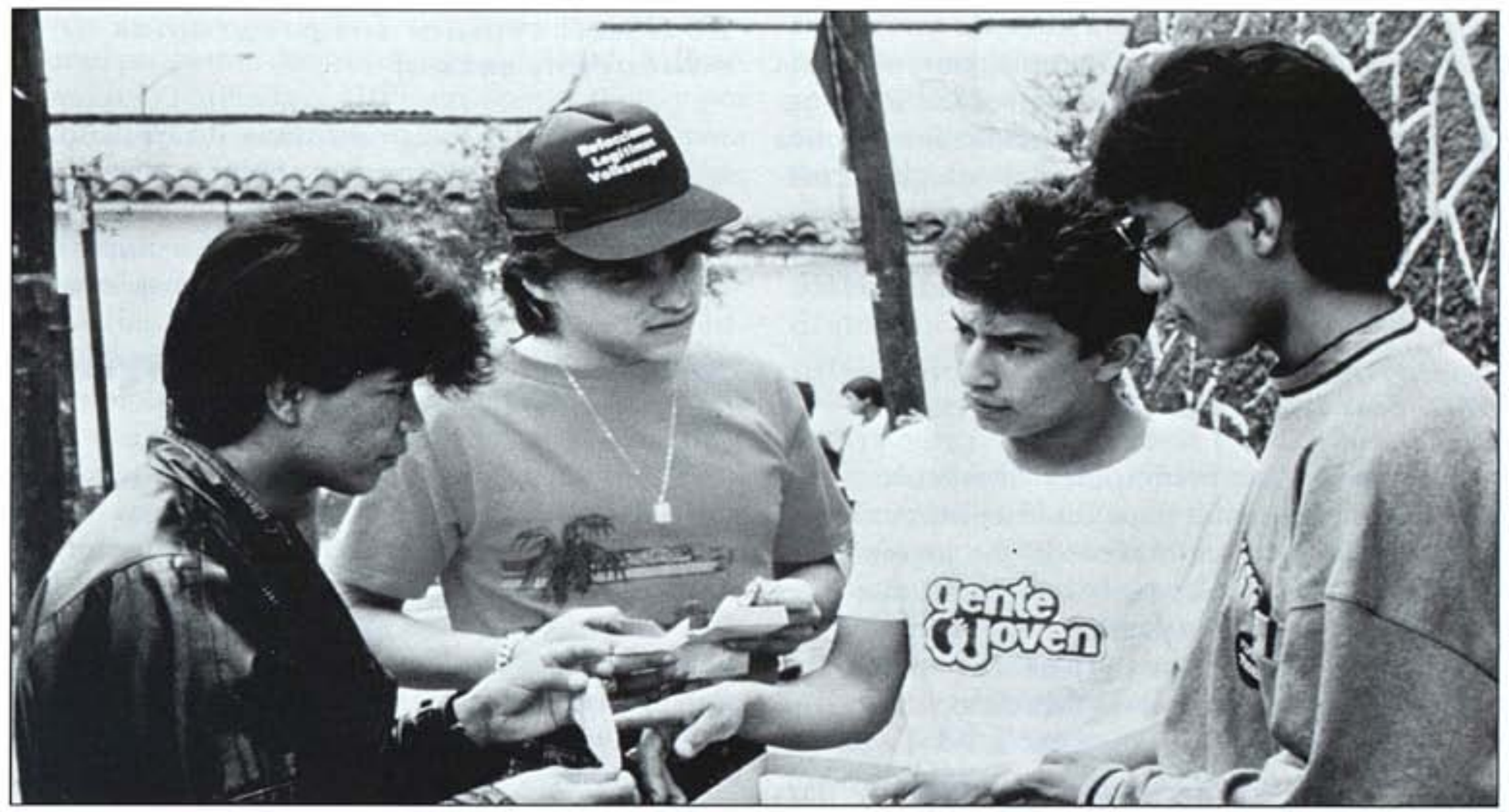

ción negativa de este tipo en México, pero el personal de Gente Joven estaba convencido de que la ayuda que el programa le proporcionaría a los adolescentes conquistaría cualquier oposición.

Por lo tanto, los promotores de Gente Joven distribuyen condones a adolescentes de por lo menos 16 años en escuelas, fábricas, centros recreativos y culturales, gimnasios y otros lugares de encuentro. Los promotores sólo entregan condones a menores de 16 años de edad si alguien lo solicita directamente. El programa sólo distribuye condones entre adolescentes porque este método no tiene efectos secundarios o contraindicaciones, y porque también protege contra enfermedades de transmisión sexual. Los promotores siempre llevan condones cuando participan en actividades del programa, por lo cual sirven no sólo como un punto de apoyo a quien los jóvenes pueden acudir con preguntas, sino que también como proveedores de anticonceptivos para jóvenes que ya han decidido tener relaciones sexuales.

$\mathrm{Al}$ principio los promotores también distribuían tabletas de espuma espermicida, pero esto resultó ser un problema porque la fecha de vencimiento de esos anticonceptivos tenía que ser rigurosamente controlada. Esto representaba una carga administrativa adicional para los coordinadores, y dado que estas tabletas y varios otros métodos anticonceptivos se pueden conseguir en las clínicas comunitarias de Mexfam, los dirigentes de Gente Joven decidieron simplificar las cosas y ofrecer sólo condones. Sin embargo, Mexfam recientemente ha estado explorando un nuevo concepto de distribución en que un condón y una tableta espermicida se combinan en un paquete atractivo, con el propósito de promover el uso simultáneo de ambos métodos. Mexfam todavía no ha podido evaluar el impacto de este concepto entre adolescentes.

Cuando un joven le indica a un promotor que tiene relaciones sexuales regulares y le pide otro tipo de anticonceptivo, el promotor lo deriva a una de las clínicas comunitarias de Mexfam, donde puede elegir un anticonceptivo apropiado para su edad, sus preferencias, su estado de salud, y su estilo de vida. Mexfam tiene un programa para médicos que recién han concluido sus estudios, en el que Mexfam les paga para iniciar prácticas en sectores rurales o marginados. Los integrantes de esta red de médicos comunitarios reciben capacitación especial en las necesidades anticonceptivas de los adolescentes. Además de anticonceptivos, las clínicas ofrecen revisaciones médicas generales, asesoramiento sobre problemas de salud reproductiva, y respuestas a cualquier otra pregunta que puedan tener. En efecto, las clínicas permiten que los jó- 
venes accedan a una amplia gama de servicios de planificación familiar en su propia comunidad y a muy bajos precios. Además de recibir información general sobre anticoncepción, los jóvenes reciben asesoramiento sobre cómo elegir un método seguro para prevenir embarazos no deseados y enfermedades de transmisión sexual, además de seguimiento médico apropiado.

\section{Los programas para adolescentes no generan ingresos económicos}

Uno de los principales obstáculos para mantener programas para adolescentes es la falta de recursos económicos de los jóvenes. La mayoría de los adolescentes no cuentan con el dinero necesario para pagar por servicios de educación sexual o anticonceptivos. El problema es especialmente grave para Mexfam, dado que Gente Joven trata de alcanzar a adolescentes marginados y de bajos ingresos. Por tal razón, Gente Joven siempre ha requerido el apoyo económico de entidades donantes en el exterior para la mayor parte de su presupuesto. En la actualidad, estas entidades incluyen la International Foundation, Moriah Fund, David and Lucille Packard Foundation, Public Welfare Foundation, Bergstrom Foundation, la Organización Japonesa para la Cooperación Internacional en Planificación Familiar y la Región Hemisferio Oeste de la International Planned Parenthood Federation. No obstante el generoso apoyo de estas entidades, Mexfam cree que el programa debe generar ingresos para cubrir por lo menos una pequeña parte de los gastos. En 1992, el presupuesto de Gente Joven alcanz6 US\$ 300.000 , y los ingresos del programa unos US\$ 6.000. Mexfam recupera gastos mediante la venta de folletos (entre US\$ 0,13 y $0,2.5$ cada uno) y otros materiales educativos a otras organizaciones. Mexfam también cobra entre US\$ 15 y US\$ 30 por los cursos de actualización profesional que ofrece a psicólogos, médicos y trabajadores sociales.

Una de las metas principales de Mexfam para la década de los 90 es mejorar la calidad de sus servicios y aumentar la autosuficiencia económica. Sin embargo, no es realista esperar que Gente Joven pueda generar ingresos importantes. El objetivo más bien seguirá siendo el de extender el alcance de las actividades del programa mediante el uso eficaz de los recursos disponibles.

\section{Es dificil evaluar los programas de educación sexual}

Dado que los programas de educación sexual se enfocan más en proveer información que en la prestación de servicios, resulta difícil evaluar su eficacia. Es más, resulta casi imposible medir el objetivo final de estos programas (el cambio de actitudes y comportamiento sexual), a través de los indicadores comúnmente utilizados. Sin embargo, Mexfam ha tratado de documentar y evaluar las actividades de Gente Joven, y todo parece indicar que el programa está teniendo un impacto positivo entre jóvenes mexicanos. Por ejemplo, Ricardo Calvillo, el coordinador de Mexfam para la región de Tlanetlaupantle, dice que "en una escuela donde el número de embarazos no deseados era muy elevado, el número de embarazos disminuyó después de la presentación de un curso de Mexfam de diez horas de duración. En 1991 (dos años y medio después del curso) sólo hubo un embarazo en la escuela de Tlanetlaupantle".

Dado que la estrategia de Gente Joven es principalmente educativa, Mexfam enfatiza los aspectos cualitativos del programa en sus evaluaciones. De todos modos, en términos cuantitativos, el departamento de evaluaciones de Mexfam notó que en 1992 solamente Gente Joven alcanzó a un total de 22.864 adolescentes de entre 10 y 19 años de edad con cursos de educación sexual de 10 horas. La evaluación también calculó que el personal de Gente Joven alcanzó a 85.548 adolescentes más por medio de presentaciones sobre sexualidad en otras escuelas. Durante el mismo año un total de 2.756 profesionales (psicólogos, trabajadores sociales y educadores) y 1.742 padres asistieron pláticas y presentaciones de Gente Joven. En la actualidad Gente Joven opera en 52 ciudades mexicanas.

La contribución de Mexfam también se puede medir en términos de la apreciación expresada por otras organizaciones en el ámbito de la educación sexual. Varios profesionales que trabajan en programas de educación sexual en otros países latinoamericanos han asistido a los cursos de capacitación de Mexfam y han solicitado ejemplares de los materiales de Gente Joven para sus propios programas. Por ejemplo, el personal de las entidades afiliadas al IPPF en Nicaragua, Colombia y Guatemala ha completado los cursos necesarios para utilizar Gente Joven. Los videos y materiales 
audiovisuales de Gente Joven han sido utilizados por el programa de prevención del SIDA de la organización afiliada al IPPF en Puerto Rico, y por varias otras organizaciones. Y el programa para adolescentes de la organización afiliada al IPPF en Colombia está adaptando la estrategia de Gente Joven para responder a las necesidades de jóvenes colombianos.

\section{Nuevos públicos, nuevas prioridades}

A lo largo de su vida institucional, Mexfam ha logrado ampliar sus servicios, diversificar sus programas, y mejorar la calidad de atención que provee al público. El programa Gente Joven ha servido como un importante estímulo en este proceso de crecimiento. Por ejemplo, la experiencia engendrada por la distribución de anticonceptivos entre adolescentes resultó en una reevaluación de la estrategia con que Mexfam distribuía anticonceptivos entre adultos. Como resultado de "Gente Joven", Mexfam decidió modificar su estrategia con adultos y enfocarla más en el usuario de la anticoncepción. La modificación requirió una reexaminación de la información entregada a clientes adultos y la capacitación proporcionada a sus proveedores de anticoncepción. La incorporación de Gente Joven a la red de servicios y actividades de Mexfam también produjo una nueva conciencia sobre las diversas necesidades anticonceptivas de otros grupos (como ser varones adultos, mujeres solteras pero sexualmente activas, etc.). Alfonso López, el director de Mexfam, resumió la influencia del programa así: "Queremos continuar en las direcciones que han demostrado buenos resultados, y vamos a concentrar nuevos esfuerzos en los programas rurales y programas dirigidos a hombres. También vamos a darle más importancia a la calidad y a mejorar la condición de la mujer".

Con ese propósito, Mexfam está evaluando todos sus programas desde una perspectiva de género y está diseñando proyectos y materiales especiales para sectores rurales. Después de seis duros años dedicados al trabajo con jóvenes mexicanos, José Aguilar está de acuerdo con estas metas: "Gente Joven debe cambiar constantemente, debe incorporar nuevas ideas y reevaluar el contenido del programa para asegurar que los materiales preparados hace cinco o seis años todavía son apropiados. También tenemos que profundizar el programa en las regiones rurales e in- cluir una perspectiva de género en nuestros programas para jóvenes". Gabriela Rodríguez está realizando un análisis de la dimensión de género en los materiales de Gente Joven y está introduciendo el "análisis de género" (7) en los cursos de capacitación del programa.

El abuso sexual y físico de los niños representa otro tema delicado que Mexfam está estudiando en relación al programa de capacitación para Gente Joven. Aunque todavía no se ha comenzado a encarar el tema, Mexfam reconoce la seriedad de estos problemas en México y ha disenado un projecto para capacitar a los proveedores de servicios de la organización en la atención requerida por víctimas de violencia y abuso sexual. Mexfam también está estudiando las maneras en que este tema se podría incorporar en el programa de Gente Joven.

En el futuro Mexfam también quisiera extender Gente Joven para incluir edades menores a las que alcanza en la actualidad. La experiencia indica que cuanto más temprano niños y niñas reciban educación sexual en un ambiente relajado y cordial, más fácil les será desarrollar una actitud positiva y sana hacia la sexualidad.

Mientras tanto, Gabriela Rodríguez ya está pensando sobre otro desafío que Gente Joven debe enfrentar: ¿Cómo delegar más responsabilidad sobre el programa a los adolescentes mismos? "En el futuro", dice Rodríguez, "debemos dar un paso gigante y darle más responsabilidad a los jóvenes. Aunque no sean capaces de producir un video o redactar materiales para el programa, lo fundamental es que los jóvenes poseen los mensajes que debemos comunicar. Los jóvenes quieren responsabilidad en la educación sexual. Un paso importante sería capacitarlos para que puedan entrenar a otros adolescentes. La verdad es que todavía somos un poco paternalistas". Una de las opciones en este sentido sería reducir el enfoque en clases formales presentadas en escuelas y elaborar estrategias para atraer jóvenes que han dejado de asistir a la escuela. Rodríguez también piensa que hace falta un mayor enfoque en los modos de expresión de los adolescentes mismos (como ser el "teatro callejero" y la música rock), especialmente entre los que no asisten a la escuela.

Mexfam también ha aprendido varias lecciones sobre el rol del promotor. En el típico programa de planificación familiar, el promotor está encargado de distribuir anticonceptivos y proveer 
información sobre servicios de planificación familiar. Esta concepción del promotor no sirve en un programa para adolescentes que busca aumentar la participación de los jóvenes y emplea un concepto de educación más complejo. Cuando se trata de alcanzar a los adolescentes, lo más importante es presentar la información de modo que sea pertinente desde el punto de vista de los jóvenes. La información sobre sexualidad debe ser colocada dentro del contexto de valores y emociones que compone el mundo de los adolescentes. Los promotores necesitan entrenamiento especial, además de mucha práctica, para poder presentar materiales educativos de este modo.

Por esa causa, Mexfam ha empezado a reducir el número de promotores de Gente Joven y a realzar el rol de los coordinadores, especialmente en cuanto al entrenamiento de maestros y trabajadores comunitarios. En la actualidad los promotores trabajan principalmente con los teatros callejeros, con el propósito de asegurar la inclusión de mensajes sobre sexualidad y salud reproductiva. El programa de Gente Joven seguirá cambiando a medida que sus integrantes aprenden nuevas lecciones, en un proceso de re- novación que enriquece al programa y le permite responder mejor a las necesidades del país.

Gente Joven dicta de ser un programa "perfecto" o un modelo que se puede duplicar en cualquier país. Gente Joven es más bien un intento constante de alcanzar uno de los sectores más sensibles y necesitados de la población mexicana, uno que suele ser muy difícil de alcanzar. Prestándole atención a la realidad mexicana, Gente Joven trata de encontrar maneras de asegurar que los adolescentes sepan más y se sientan más comodos con sus cuerpos y su sexualidad, para que puedan tomar decisiones objetivas sobre su comportamiento sexual, la anticoncepción y la prevención de enfermedades.

El personal de Gente Joven reconoce que todavía tiene mucho que aprender de parte de otros profesionales con experiencia en este ámbito y de parte de los jóvenes mismos. El programa busca mantener una estructura abierta, capaz de incorporar nueva información, nuevas metodologías y estrategias diferentes. Los errores se aceptan como parte del riesgo inherente en un programa dinámico. Lo importante es permanecer abiertos y concientes al hecho de que siempre es posible mejorar.

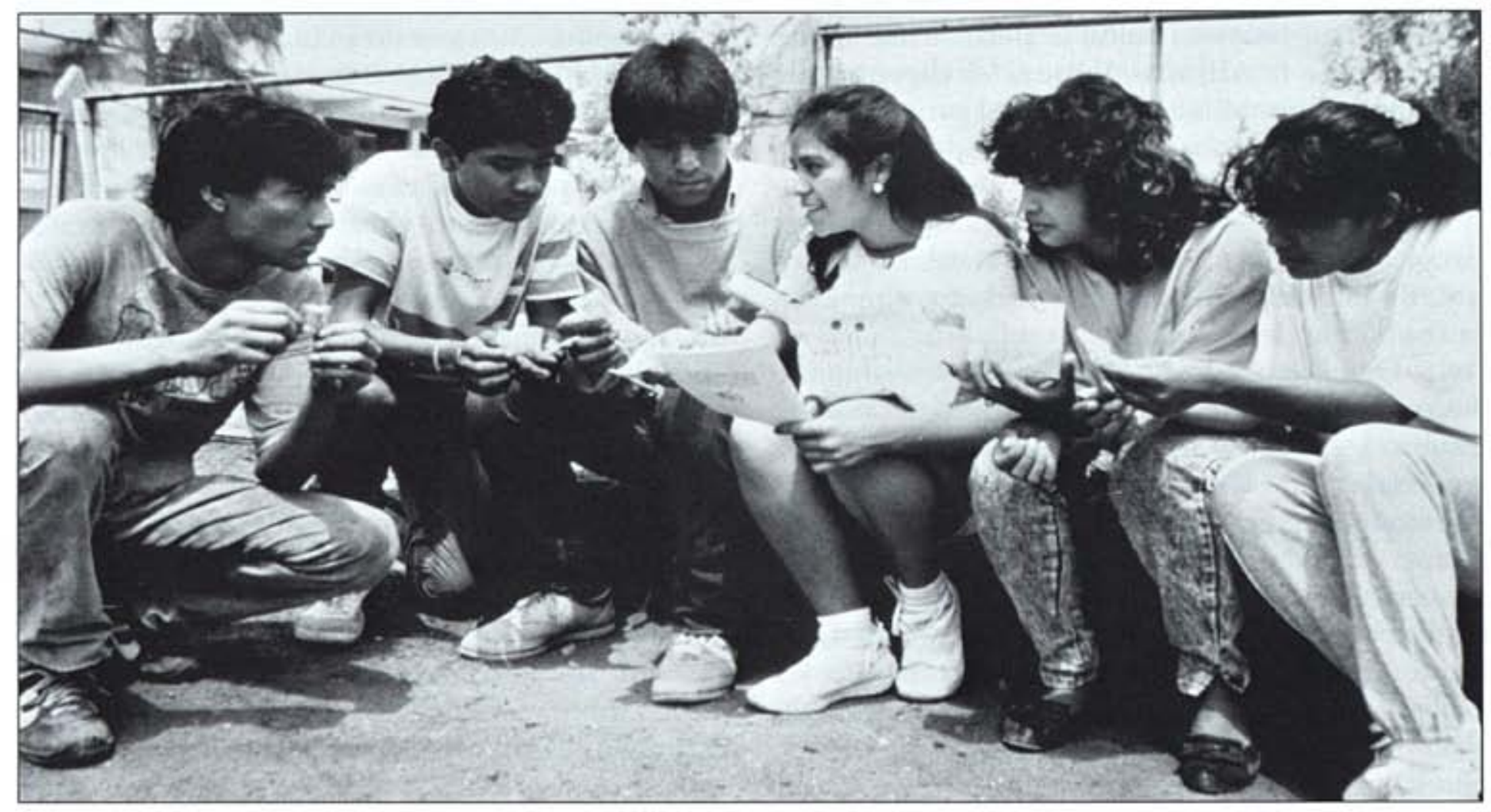




\section{Conclusión}

Con su énfasis en escuchar a los jóvenes, Gente Joven le ha prestado mucha atención a las diferencias entre las necesidades de adultos y adolescentes. Pero después de siete años de experiencia y reflexión, el personal del programa está cada vez más conciente del hecho de que los "adolescentes" no constituyen un grupo homogéneo. Aunque Gente Joven ya distingue entre las realidades de jóvenes que asisten o no asisten a la escuela, el personal está empezando a redefinir el programa en reconocimiento de otros factores que diferencian a los adolescentes. Estos factores incluyen distintas percepciones, experiencias, riesgos $y$ necesidades que definen la identidad y sexualidad de los adolescentes. Esta conclusión busca esclarecer algunas de las cuestiones prácticas y teóricas que programas como Gente Joven enfrentan cuando sus líderes comienzan a reexaminar la sexualidad adolescente desde una perspectiva de género.

\section{¿Quién ejerce control?}

Desde la infancia, los varones reciben mensajes que les dan un sentido de control sobre sí mismos y sobre otros, mientras que las niñas aprenden a renunciar al control. Cuando llegan a la adolescencia, la idea de lo que una muchacha o un muchacho "deben ser" ya está bastante arraigada en los jóvenes. En un experimento educativo en los Estados Unidos, se les pidió a varios grupos de varones que respondieran a la siguiente pregunta: "Si de repente te convirtieras en una niña, ¿cómo sería tu vida?" Algunos varones se mostraron deprimidos con la pregunta, y muchos no lograron formular una respuesta. Pero cuando varios grupos de muchachas tuvieron que contestar la misma pregunta en forma inversa, la mayor parte describió con entusiasmo las aventuras y hazañas que podrían realizar si fueran varones.

Cuando las niñas llegan a ser mujeres, la cuestión de "control" aparece también en el ámbito laboral. Las muchachas que han participado en Gente Joven dicen que las mujeres quieren trabajar porque esto les ofrece una oportunidad para "desarrollarse" como individuos. Sin embargo, las muchachas también saben que los varones suelen oponerse a que ellas trabajen, porque "los varones temen que si trabajamos vamos a iniciar amistades con otros varones". Desde muy jóve- nes, las mujeres aprenden a vivir con las sospechas de los varones, ya que ellos interpretan como desleal cualquier asociación con otros varones.

Para las mujeres, esta concepción negativa y limitada de la vida obra en contra de la autodeterminación e igualdad en cuestiones de sexualidad. Muchas adolescentes internalizan la idea de que no deben tener control sobre lo que les ocurre en cuanto al sexo. En América Latina, el primer contacto sexual de la adolescente típica ocurre con un muchacho dos o tres años mayor. Esta desventaja en la edad hace aún menos probable que una muchacha pueda negociar sus decisiones sexuales efectivamente, o que pueda decidir independientemente si quiere o no usar anticoncepción. Es más, en muchas situaciones las muchachas prefieren evitar el tema de la anticoncepción en general, ya que temen que sus parejas las acusen de tener "demasiada experiencia" si demuestran familiaridad con el tema. Para desarrollar una conciencia sobre las diferencias que el género impone entre varones y muchachas, los programas como Gente Joven pueden contestar preguntas como las siguientes: ¿Tiene sentido definir la adolescencia como "la etapa de vida en que uno decide lo que quiere ser"? ¿Son distintas las reacciones de varones y mujeres ante cursos como "Planeando tu vida"? ¿Qué nos dicen las dinámicas del poder y género sobre la actividad sexual de mujeres adolescentes? ¿Es posible que la pasividad que la sociedad les inculca a las mujeres termine por exponerlas a las enfermedades de transmisión sexual, el SIDA y la violencia física? ¿Tiene sentido que los programas para adolescentes se encarguen de estas cuestiones?

Los padres también contribuyen a la dinámica del género, ya que suelen controlar el comportamiento de sus hijas mucho más que el de sus hijos, especialmente cuando se trata de sexualidad y fecundidad. Muchos padres mantienen distintas normas para hijos e hijas; las normas para las hijas casi siempre son mucho más estrictas. Aunque existen muchas técnicas y estrategias eficaces para mejorar la comunicación entre padres e hijos, quizás valga la pena que Gente Joven vuelva a examinar sus intentos en este ámbito desde una perspectiva de género. La promoción de comunicación clara y abierta "entre padres e hijos", ¿tiene un significado distinto para hijas e hijos? ¿Tiene sentido distribuir materiales para padres sobre la comunicación con sus hijos, sin distinguir entre hijos e hijas? 


\section{¿Quién tiene responsabilidad?}

Los varones y las mujeres también heredan distintas responsabilidades en cuanto a la crianza de niños y el apoyo de la familia, pero en muchos casos las muchachas tienen ilusiones sobre estos roles que distan de la realidad. Por ejemplo, ¿cuántas muchachas suponen que con el matrimonio vienen los hijos y con los hijos viene el apoyo económico sostenido del esposo? ¿Cuántas muchachas mexicanas saben que probablemente van a pasar la gran parte de sus vidas trabajando para apoyar a sus familias y a sí mismas? ¿Cuántas entienden el riesgo de quedar separadas de sus esposos? ¿Cuántos jóvenes varones entienden y están cómodos con sus deberes como "padres" y proveedores para sus familias? Las instituciones religiosas y públicas siguen aferrándose a un modelo de la "familia tradicional" que en realidad nunca existió para muchos individuos, mientras que las verdaderas familias de hoy se encuentran acosadas por presiones económicas y sociales cada vez más fuertes. En este contexto, los cursos para "planear la vida" deben educar a los jóvenes sobre quién realmente va a pagar la crianza de los hijos.

Gente Joven está aprendiendo mucho sobre cómo representar la realidad sin perder su conciencia crítica y su visión de cambio. El personal del programa escuchó a los jóvenes cuando estos dijeron que la conclusión romántica y "neutral al género" de la película "El último tren" (en la que el muchacho se queda con su novia embarazada para enfrentar un futuro incierto), no era más que una fantasía. En el video "Música para dos", una adolescente en escuela secundaria debe decidir entre dos muchachos. Muchas sociedades todavía se oponen a que las mujeres sueñen con establecer una identidad individual. Sin embargo, además de alentar a las mujeres jóvenes a que elijan la pareja que más les conviene, ¿no deberíamos también presentarles la opción de postergar la actividad sexual si no están listas? En vez de la tradicional prohibición contra el sexo para mujeres jóvenes, ¿ No sería mejor presentar la abstención sexual como una opción positiva? En una sociedad donde los medios y los amigos ejercen una presión contínua en pro de la actividad sexual, muchos jóvenes aprecian cualquier apoyo que puedan recibir si deciden postergar el sexo. Este apoyo es tan importante como el que podemos proveer para jóvenes que han decidido iniciar su vida sexual y necesitan ayuda para deci- dir cómo manejarla. Debemos tener cuidado de no reforzar la noción de que el "éxito", para una mujer, equivale a encontrar un buen hombre. Los dirigentes de cualquier programa como Gente Joven deben hacer una pausa de vez en cuando y preguntarse lo siguiente: “ ¿Es hora de ir más allá de las ilusiones populares sobre la vida y el amor, o es hora de validarlas?"

Las respuestas no siempre son fáciles. Por ejemplo, al proveer condones a través de Gente Joven, Mexfam cruzó la línea que separa a los programas que se limitan a "ofrecer sólo información" de los que ofrecen tanto información como servicios. Pero la decisión de sólo ofrecer condones puede haber transmitido un mensaje contradictorio. El programa dejó de distribuir tabletas espermicidas femeninas por una cuestión práctica (las fechas de vencimiento). Esta decisión surgió de buenas intenciones: se buscaba asegurar buena calidad y promover la responsabilidad de los varones. Pero a la misma vez, la decisión significó que Gente Joven no ofrecería un método anticonceptivo controlado por la mujer.

La disponibilidad de dichas tabletas, aun si muy pocas muchachas optaran por utilizarlas, tendría un potente valor simbólico, al indicar que las muchachas tienen el derecho a tomar la iniciativa y protegerse con un método que requiere que ellas mismas manipulen sus órganos genitales. La confianza que las muchachas lograrían en el uso de este tipo de método también podría abrir paso para el uso futuro de otros métodos controlados por la mujer, como ser los microbicidas anti-VIH actualmente en desarrollo. Gente Joven está explorando la posibilidad de ofrecer un nuevo "paquete combinación" que contiene condones y tabletas espermicidas.

\section{¿A quién estamos silenciando?}

Finalmente, existe otra incómoda dimensión de la sexualidad de muchas mujeres adolescentes (y algunos varones) que casi todos los programas de fecundidad adolescente dejan sin explorar: el abuso sexual y el incesto. Para los millones de adolescentes que han sido víctimas del abuso sexual, una defensa del "derecho" a la actividad sexual puede sonar desubicada o, en el peor de los casos, les puede parecer una negación activa del dolor de su propia experiencia. Estos adolescentes ya han perdido cualquier sentido de autonomía; es importante que los programas para ado- 


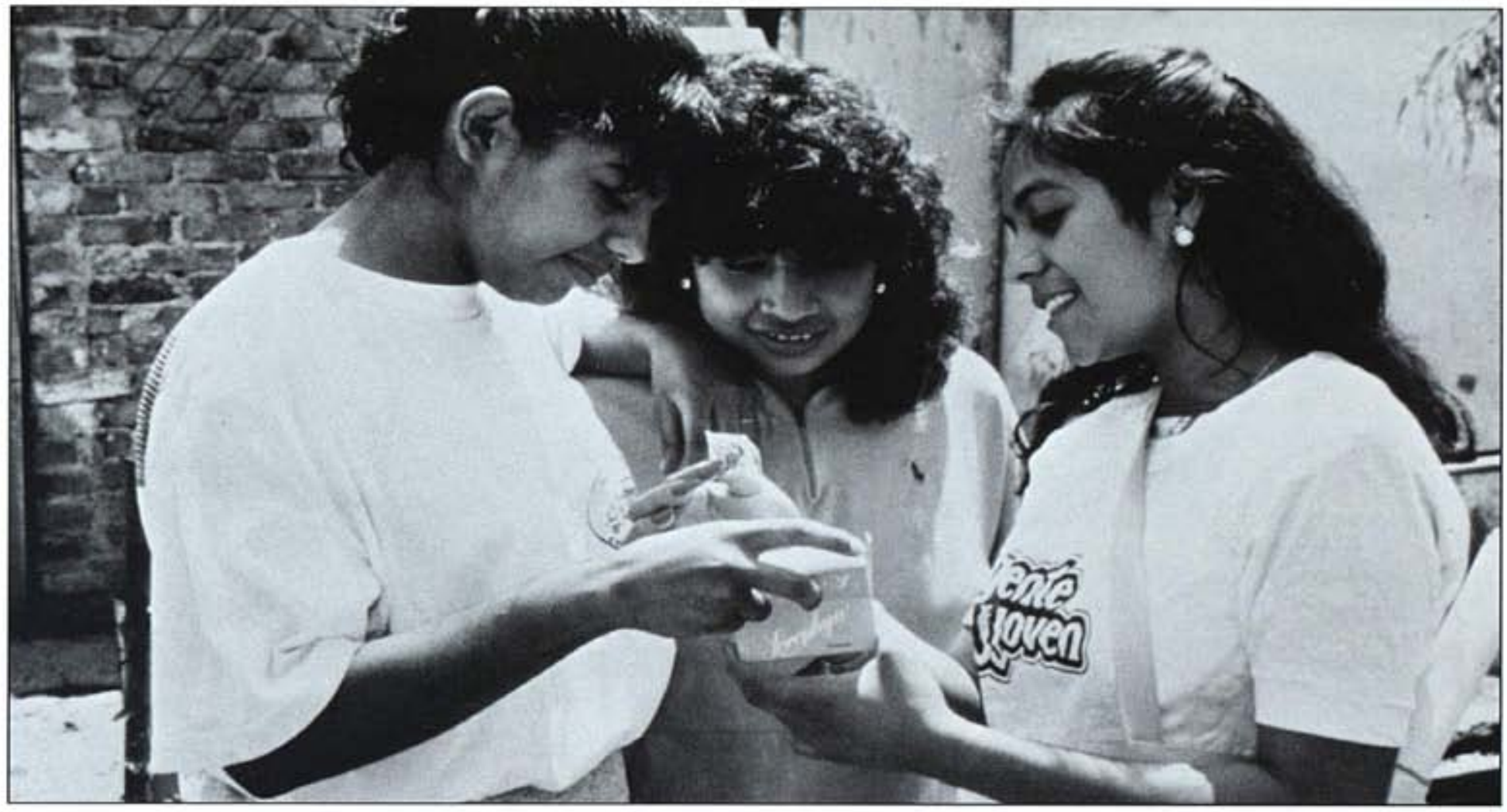

lescentes no profundicen el silencio, la confusión y la vergüenza de estos jóvenes al no reconocer su realidad. Dichos programas deben incorporar mecanismos que permitan que las víctimas del abuso sexual reconozcan esas experiencias y puedan validar sus emociones.

Aunque muchos programas carecen de la capacidad y los recursos necesarios para atender directamente a estos temas, el apoyo moral y un sistema de derivaciones a profesionales apropiados puede ayudar a que estos jóvenes desarrollen un sentido de autonomía y control sobre sus propios cuerpos. Dicha política también puede ayudar a evitar muchos embarazos precoces. En un estudio estadounidense de madres adolescentes, dos tercios de las entrevistadas habían sido abusadas sexualmente, en muchos casos por parientes cercanos. Esa proporción de casos es típica en muchas sociedades.

Dentro del ámbito de los programas para adolescentes, ¿Estamos preparados para reconocer que el abuso sexual, y particularmente el incesto, suelen anticipar la actividad sexual y el embarazo precoz? ¿Estamos listos para discutir con mujeres adolescentes el "riesgo" físico o emocional que sienten en relación a hombres que conocen más o menos íntimamente, incluso dentro de sus propias familias? Muchas mujeres, y especialmente mujeres jóvenes, pueden empezar a superar el dolor del abuso sexual y construir un nuevo sentido de autoestima a través de conexiones con otras mujeres fuera de la familia, en la escuela o en otras organizaciones comunitarias.

$\mathrm{Al}$ reconocer la urgencia de enfrentar cuestiones de género con seriedad, Gente Joven está acercándose a una estrategia programática más efectiva pero a la vez más radical. El proceso de comprensión de las dinámicas de poder entre hombres y mujeres requiere coraje y claridad. Antes de desafiar las desigualidades de estas dinámicas debemos identificarlas explícitamente. El estudio honesto de las experiencias íntimas entre muchachos y muchachas ayudará, en última instancia, a que ambos grupos tengan vidas más plenas, placenteras y productivas.

\section{Notas}

'Este dato fue confirmado por el INEGI de 1991. Censo Ceneral de Población y Vivienda, Mexico.

'Alan Guttmacher Institute, Today's Adolescents, Tomorrow's Parents: A Portrait of the Americas, 1990.

Alan Guttmacher Institute, 1990.

${ }^{4}$ Pick de Weiss, y otros, Planeando Tu Vida, Limusa, México, 1991

"Lucille C. Atkin, "El embarazo en la adolescencia en América Latina y el Caribe: causas y consecuencias psicosociales". En Conferencia Internacional sobre Fecundidad en Adolescentes en América Latina y el Caribe. Pathfinder Fund/Population Council, noviembre de 1989.

"Pick de Weiss, y otros, "Sex, Contraception, and Pregnancy Among Adolescents in Mexico City", en Studies in Family Planning, v. 22. n. 2, 1991 .

${ }^{7}$ Este análisis de las diferencias entre los sexos permite una comprensión de los distintos roles sociales que los varones y las mujeres aprenden a aceptar. Los roles que surgen del género constituyen una construcción social y no deben confundirse con las diferencias sexuales biológicas. 


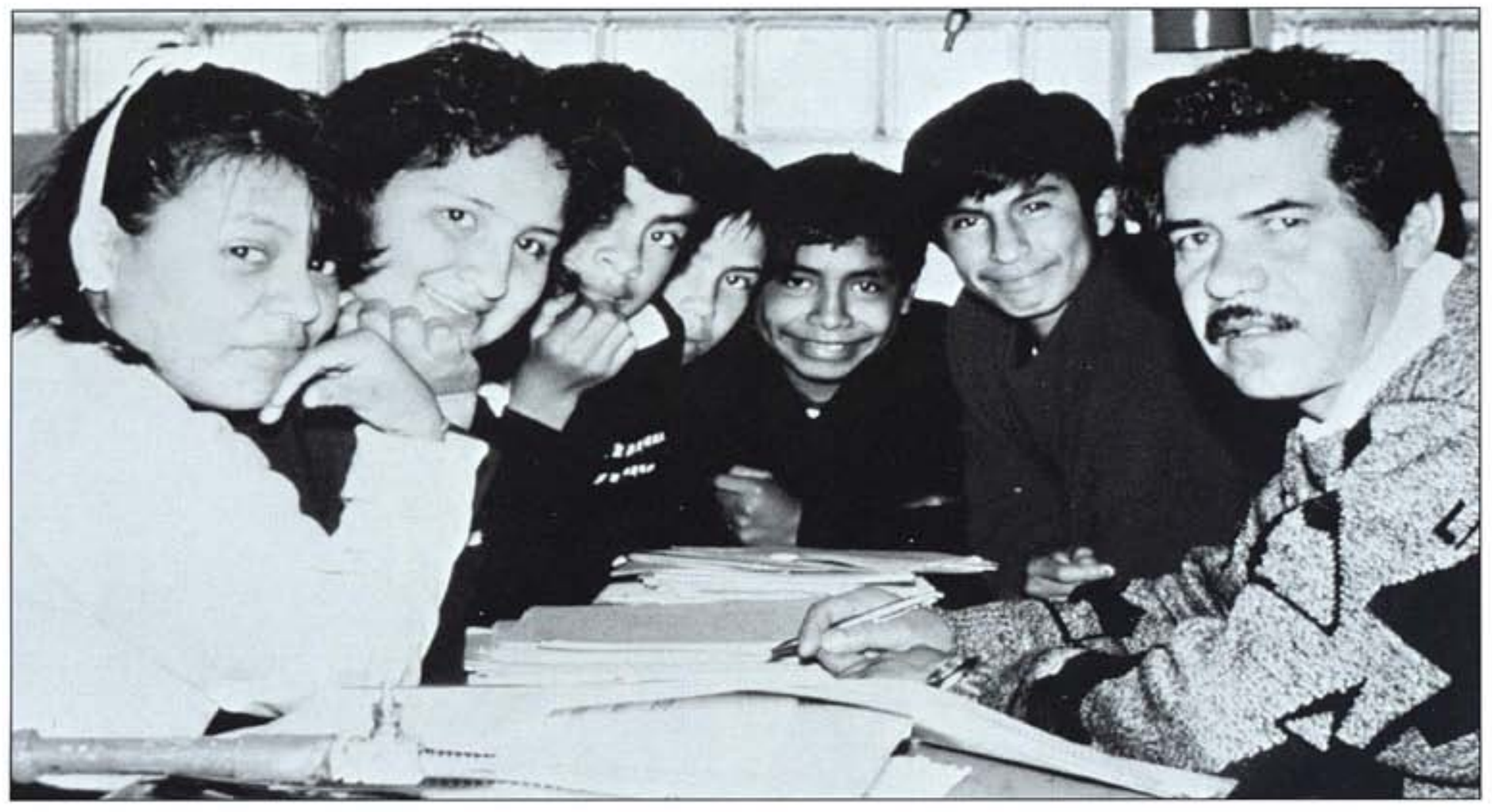

\section{Referencia}

Si usted desea mas información sobre el programa Gente Joven, esta disponible de: Gabriela Rodriguez, Mexfam, Calle Juarez 208, Tlalpan, Mexico 14000 D.F Mexico, Telephone (525) 573-7070; FAX (525) 573-2318. 


\section{Otras Ediciónes de QUALITY/CALIDAD/QUALITE}

1. Celebrating Mother and Child on the Fortieth Day: The Sfax Tunisia Postpartum Program by Francine Coeytaux, Introduction and Afterword by Beverly Winikoff, M.D., 1989. (Disponible en inglés; el texto en español y francés esta disponible solamente en forma de manuscrito)

2. Man/Hombre/Homme: Meeting Male Reproductive Health Care Needs in Latin America by Debbie Rogow, Introduction and Afterword by Judith Bruce and Ann Leonard, 1990. (Disponsible en inglés y español)

3. The Bangladesh Women's Health Coalition by Bonnie J. Kay, Adrienne Germain and Maggie Bangser, 1991. (Disponsible en inglés)

4. By and for Women: Involving Women in the Development of Reproductive Health Care Materials, Case Studies by Barbara Ibrahim and Nadia Farah (Egypt), Blanca Figueroa (Peru), Margaret Winn (South Pacific), Introduction and Afterword by Valerie Hull, 1992. (Disponsible en inglés)

5. Gente Joven/Young People: A Dialogue on Sexuality with Adolescents in Mexico by Magaly Marques, Introduction by John M. Paxman and Afterword by Judith Bruce, 1993. (Disponsible en inglés y español)

6. The Coletivo: A Feminist Sexuality and Health Collective in Brazil by Margarita Diaz and Debbie Rogow, Introduction by José Barzelatto, 1995. (Disponsible en inglés y portugués)

7. Doing More with Less: The Marie Stopes Clinics of Sierra Leone by Nahid Toubia, Introduction by Grace Eban Delano, 1995. (Disponsible en inglés)

8. Introducing Sexuality within Family Planning: Three Positive Experiences from Latin America and the Caribbean. (En lo venidero, en inglés y español)

(Cada edición en inglés incluye un resumido, de una pájina, en español y francés) 



\section{Sobre las Autoras}

Magaly Marques trabaja en la gerencia de programas de la International Planned Parenthood Federation, Región Hemisferio Oeste. Marques asesora a varios programas de planificación familiar en la región, con un interés particular en cuestiones de género, derechos y salud reproductiva de la mujer.

John M. Paxman, J.D., es Profesor Adjunto de Servicios de Salud en la Boston University School of Public Health, además de Director de Keene Associates en Lexington, Massachusetts. Paxman ha trabajado en programas para adolescentes en varias partes del mundo. Judith Bruce es una Asociada del Population Council interesada especialmente en los roles y la condición de la mujer y la calidad de atención.

\section{Comité asesor de Quality/Calidad/Qualité}

Ian Askew
Karen Beattie
Martha Brady
Geeta Rao Gupta
Judith Bruce
Christa Coggins
Adrienne Germain
Karen Stein
Lindsay Stewart
Kerstin Trone
Nahid Toubia
Gilberte Vansintejan
Elizabeth McGrory
Kirsten Moore

\author{
Nancy Newton \\ John Paxman \\ George Brown \\ Julie Reich \\ Debbie Rogow \\ Jill Sheffield \\ Cynthia Steele Verme \\ Joan Haffey \\ Margaret Hempel \\ Ann Leonard \\ Magaly Marques \\ Margaret McEvoy \\ Beverly Winikoff \\ Margot Zimmerman
}

$\begin{array}{ll}\text { Diseño: } & \text { Ann Leonard } \\ \text { Fotos: } & \text { Mexfam } \\ \text { Impresión: } & \text { Graphic Impressions } \\ \text { Traducción: } & \text { Paul Constance } \\ \text { Tipografía: } & \text { Heidi Neurauter }\end{array}$

Solicitamos sus comentarios e ideas sobre proyectos que podrían ser incluidos en futuras ediciones de Quality/Calidad/Qualité. Si desea recibir ejemplares adicionales de esta edición o quisiera ser incluido en nuestra lista postal, favor de escribir a: Ann Leonard, Editor, Quality/Calidad/Qualité, The Population Council, One Dag Hammarskjold Plaza, New York, NY 10017 U.S.A. 
